\title{
Vegetation dynamic analysis based on multisource remote sensing data in the east margin of the Qinghai-Tibet Plateau, China
}

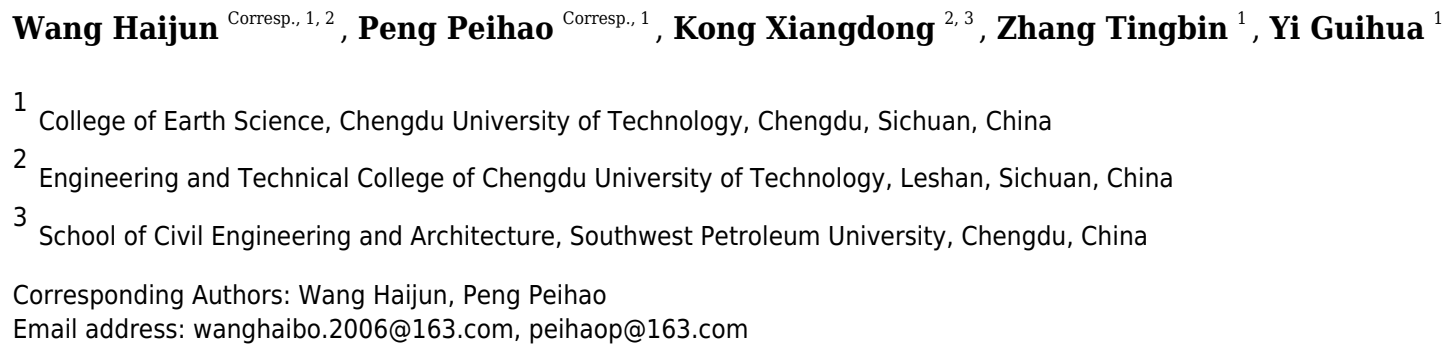

This study focuses on the vegetation dynamic caused by global environmental change in the eastern margin of the Qinghai-Tibet Plateau (EMQTP). The Qinghai-Tibet Plateau (QTP) is one of the most sensitive areas responding to global environmental change, particularly global climate change, and has been recognized as a hotspot for coupled studies on changes in global terrestrial ecosystems and global climates. An important component of terrestrial ecosystems, vegetation dynamic has become a key issue in global environmental change, and numerous case studies have been conducted on vegetation dynamic trends using multi-source data and multi-scale methods across different study periods. The EMQTP is regarded as a transitional area located between the QTP and the Sichuan basin, and has special geographical and climatic conditions. Although this area is ecologically fragile and sensitive to climate change, few studies about vegetation dynamics have been carried out in this area. Thus, in this study, we used long-term series datasets of GIMMS $3 g$ NDVI and VGT/PROBA-V NDVI to analyze the vegetation dynamics and phenological changes from 1982 to 2018. Validation was performed based on Landsat NDVI and Vegetation Index \& Phenology (VIP) data. The results reveal that the year 1998 was a vital turning point in the start of growing season (SGS) in vegetation ecosystems. Before this turning point, the SGS had an average slope of 9.2 days/decade, and after, the average slope was 3.9 days/decade. The length of growing season (LGS) was slightly prolonged between 1982 to 2015. Additionally, the largest national alpine wetland grassland experienced significant vegetation degradation; in autumn, the degraded area accounted for $63.4 \%$. Vegetation degradation had also appeared in the arid valleys of the Yalong River and the Jinsha River. Through validation analysis, we found that the main causes of vegetation degradation are the natural degradation of wetland grassland and human activities, specifically agricultural development and residential area expansion. 
1 Vegetation dynamic analysis based on multisource remote sensing data in the east

2

4

\title{
margin of the Qinghai-Tibet Plateau, China
}

\author{
Haijun Wang ${ }^{1,2}$, Peihao Peng ${ }^{1}$, Xiangdong Kong, ${ }^{2,3}$, Tingbin Zhang ${ }^{1,2}$ and Guihua Yi ${ }^{1}$
}

${ }^{1}$ College of Earth Science, Chengdu University of Technology, Chengdu, Sichuan, China

${ }^{2}$ Engineering and Technical College of Chengdu University of Technology, Leshan, Sichuan, China

${ }^{3}$ School of Civil Engineering and Architecture, Southwest Petroleum University, Chengdu, China Haijun Wang ${ }^{1,2}$ and Peihao Peng ${ }^{1}$

Chengdu, Sichuan Province, China

Email address: wanghaibo.2006@163.com, peihaop@163.com.

\section{Abstract}

This study focuses on the vegetation dynamic caused by global environmental change in the eastern margin of the Qinghai-Tibet Plateau (EMQTP). The Qinghai-Tibet Plateau (QTP) is one of the most sensitive areas responding to global environmental change, particularly global climate change, and has been recognized as a hotspot for coupled studies on changes in global terrestrial ecosystems and global climates. An important component of terrestrial ecosystems, vegetation dynamic has become a key issue in global environmental change, and numerous case studies have been conducted on vegetation dynamic trends using multi-source data and multi-scale methods across different study periods. The EMQTP is regarded as a transitional area located between the QTP and the Sichuan basin, and has special geographical and climatic conditions. Although this area is ecologically fragile and sensitive to climate change, few studies about vegetation dynamics have been carried out in this area. Thus, in this study, we used long-term series datasets of GIMMS $3 g$ NDVI and VGT/PROBA-V NDVI to analyze the vegetation dynamics and phenological changes from 1982 to 2018. Validation was performed based on Landsat NDVI and Vegetation Index \& Phenology (VIP) data. The results reveal that the year 1998 was a vital turning point in the start of growing season (SGS) in vegetation ecosystems. Before this turning point, the SGS had an average slope of 9.2 days/decade, and after, the average slope was 3.9 days/decade. The length of growing season (LGS) was slightly prolonged between 1982 to 2015. Additionally, the largest national alpine wetland grassland experienced significant vegetation degradation; in autumn, the degraded area accounted for $63.4 \%$. Vegetation degradation had also appeared in the arid valleys of the Yalong River and the Jinsha River. Through validation analysis, we found that the main causes of vegetation degradation are the natural degradation of wetland grassland and human activities, specifically agricultural development and residential area expansion.

\section{Introduction}

Vegetation is the main component of terrestrial ecosystems on earth (Piao et al., 2003), playing a crucial role in energy exchange, water cycles and biological cycles on the terrestrial surface. Vegetation connects the atmosphere, hydrosphere and biosphere, and is vital for reducing greenhouse gases, regulating carbon balance, and maintaining climate stability at the global scale (Hu et al., 2010). Vegetation dynamics are especially sensitive to climate change (Yang and Piao, 2006) and, in recent years, have been regarded as the key element in the global changes of terrestrial ecosystems (Kelly et al., 2011; Li et al., 2019).

PeerJ reviewing PDF | (2019:04:36681:2:2:REVIEW 24 Oct 2019) 
Because of its long-term series span and large area coverage, remote sensing data has become a common and vitally important data source in the field of vegetation dynamics monitoring (Casa et al., 2018). The normalized difference vegetation index (NDVI) is widely used as a parameter of vegetation dynamics and refers to the quantitative values of vegetation conditions. It is often obtained through a combination of different spectral remote sensing data. Due to its sensitivity to vegetation growth status, phenology changes, and vegetation cover change (Tucker, 1979), NDVI has been the most widely applied indicator used to represent vegetation status among various other vegetation indices. Global Inventory Monitoring and Modeling Studies (GIMMS) 3g NDVI and SPOT VGEATION (VGT) NDVI have been acknowledged as the most widely used remote sensing data products (Casa et al., 2018; Chavez et al., 2019), being used to monitor vegetation dynamics at both regional and global scales (Liu et al., 2017; Wu et al., 2016). GIMMS NDVI data cover a large time span from 1982 to 2015, and VGT NDVI has higher spatial and temporal resolutions.

One of the most sensitive areas responding to global environmental change (Yang and Piao, 2006; Li et al., 2019), the QTP has been recognized as a hotspot for vegetation dynamics. Peng et al. used the Hurst exponent to analyze the trend of vegetation dynamics (Peng et al., 2012), and an eco-environmental vulnerability change was performed in the Sanjiangyuan region of the QTP based on Liu's fuzzy analytic hierarchy process (Liu et al., 2017). Shen and colleagues looked at the spring vegetation phenology change in the QTP in the last decade (Shen et al., 2014), and the response of artificial vegetation to changes in the ecological environment of the QTP was studied by Liu (Li et al., 2017). The EMQTP is a transitional zone reaching from the Sichuan basin to the QTP (Li et al., 2019; Amelie et al., 2009). It belongs in the Qinghai-Tibet Plateau climate zone and is affected by southeast monsoons. The largest alpine wetland and natural pasture are located in the EMQTP, and alpine and subalpine meadows are the dominant vegetation in this area. Additionally, this area contains the important Yangtze and Yellow Rivers. This area has special conditions that make it suitable for the research of terrestrial ecosystems, particularly wetland changes and vegetation dynamics. The terrestrial ecosystem of the QTP has also transformed (Li et al., 2019; Fei et al., 2018) with the current backdrop of global climate change (IPCC, 2014). How has the terrestrial ecosystem, specifically the vegetation, of the EMQTP (a transitional and special area) changed? The answer to this question has significant meaning for the ecological protection of the river source area. However, few studies have focused on this area for vegetation dynamic research. Previously, Peng analyzed vegetation change trends from 1982 to 2001, and tested the results by $P$ values in the QTP area (Peng et al., 2012). This was a well-executed study, but has two vital problems that need to be discussed: first, the $P$ value test may be unreliable since it is easy to pass (Chris, 2015), necessitating the reevaluation of the significance of the vegetation change trend; second, the NDVI statistics for the various vegetation were not described clearly. Were statistics taken at a site scale or at a regional scale? This ambiguity brings into question the validity of the results.

In this work, we studied the EMQTP (a sub-area of the QTP) (Fig. 1) using multisource NDVI images and a semi-innovative approach to analyze vegetation dynamic trends between 1982 to 2018. More specifically, this study attempted to address the following questions:

(1) What was the multi-scale phenological change of the study area?

(2) What were the temporal-spatial dynamics of different vegetation?

\section{Materials \& Methodologies}

PeerJ reviewing PDF | (2019:04:36681:2:2:REVIEW 24 Oct 2019) 
81

82

83

84

85

86

87

88

89

90

91

92

93

94

95

96

97

98

99

100

101

102

103

104

105

106

107

108

109

110

111

112

113

114

115

116

117

118

119

120

\subsection{Study area}

The EMQTP (Fig. 1) extends from Hengduan Mountain to Qilian Mountain $\left(26.1-36.2^{\circ} \mathrm{E}, 94.0-\right.$ $\left.104.4^{\circ} \mathrm{N}\right)$. It includes the Ganzi, Aba autonomous prefecture of Sichuan province, and parts of Qinghai Province and Tibet. This is the source region for some important rivers, such as Yangtze River and the Yellow River. Moreover, this region is the largest natural pasture and has the largest alpine wetland grassland in China, and alpine and sub-alpine meadows dominate this area. Frequent human activities and climate changes in this area have caused transformations in the vegetation cover and degradation to the grassland. This area has been defined as a typical ecologically fragile area by the government, and accordingly needs to be researched and protected.

2.2. Image and processing

2.2.1. Image sources

(1) GIMMS 3g NDVI dataset

The most recent version of the Global Inventory Modeling and Mapping Studies (GIMMS) 3g NDVI (NASA-NEX, 2019) (January 1982 to December 2015) by AVHRR sensor was the dataset used in this study. The $3 \mathrm{~g}$ data were produced in a geographical coordinate with a 15-day interval and a spatial resolution of $0.083^{\circ} \times 0.083^{\circ}$ per pixel, and had been submitted to atmospheric and radiometric correction. The $3 g$ NDVI data were generated to improve the reliability for areas with short growing seasons (Zheng et al., 2017; Florian et al., 2016; Du et al., 2015). The 3g NDVI data processed using MVC methods generated monthly NDVI values. This process eliminated the effects of atmosphere, clouds, soil, and snow. The $3 g$ data were downloaded from ECOCAST (https://ecocast.arc.nasa.gov).

\section{(2) SPOT VGT \PROBA-V NDVI dataset}

Other long-term NDVI series datasets used in this study were the SPOT VGT (S10) and PROBA-V, a 10-day composite NDVI dataset taken at a spatial resolution of $1 \times 1 \mathrm{~km}$ from the period of April 1998 to October 2018. The quality of the VGT NDVI dataset in terms of geometry and radiometry processing for directional and atmospheric effects marks it as an excellent instrument for monitoring forests, grasses, and crops (VITO, 2018). Additionally, the PROBA-V NDVI (PROBA-V Products User Manual, 2018) data at $1 \mathrm{~km}$ resolution were also used in this study to extend the monitoring time. A PROBA-V satellite was launched in May 2013 to plug the gap between SPOT-VGT and Sentinel-3 satellites. The two NDVI datasets were generated using the MVC method (Holben,1986), as MVC was confirmed as a reliable and practical method from many previous studies. The VGT $\backslash$ PROBA-V NDVI dataset has been used widely in forest, grassland and crop dynamic studies largely due to its high quality (PROBA-V Products User Manual, 2018). The data were downloaded from VITO Earth Observation (http://www.vito-eodata.be).

(3) Data Engine of VIP Lab.

The data engine of the VIP (Vegetation Index \& Phenology) Laboratory provides phenology data at a global range using a three-dimensional grid. The VIP product (VIP Lab, 2011) was generated based on the AVHRR (Advanced Very High-Resolution Radiometer) dataset with a spatial resolution of $0.05^{\circ} \times 0.05^{\circ}$ per pixel. This is a yearly phenology product with a time span from 1982 to 2015 . This product includes the start of season, end of season, and the day of peak. VIP phenology products are available from the Vegetation Index \& Phenology Lab (https://vip.arizona.edu).

(4) Landsat NDVI

Peer] reviewing PDF | (2019:04:36681:2:2:REVIEW 24 Oct 2019) 
Landsat Thematic Mapper (TM) and Operational Land Imager (OLI) data were used to validate the NDVI-based (GIMMS $3 \mathrm{~g}$ and VGT $\backslash$ PROB-V) vegetation dynamic trends. The Landsat 5 (L5) image consists of seven bands with a spatial resolution of $30 \mathrm{~m}$. Band $3(0.63-0.69 \mu \mathrm{m})$ is in the red (R) spectrum, and band $4(0.76-0.90 \mu \mathrm{m})$ is near the infrared red (NIR) spectrum. Landsat 8 (L8) OLI includes nine bands with a spatial resolution of $30 \mathrm{~m}$. Among them, Band 4 is in the R spectrum $(0.63-0.68 \mu \mathrm{m})$ and Band 5 is in the NIR spectrum $(0.845-0.885 \mu \mathrm{m})$. We used NIR and R band to calculate NDVI, and validation was performed based on this vegetation index. The study area is covered by a large number of clouds, especially in summer, and we needed to select images with less than 5\% clouds from the USGS website. The basic information of the images downloaded, including the orbital number, sensor type, and image acquisition date, are shown in Table 1.

(5) Vegetation and topographic maps

The vegetation vector map is at 1: 100000 scale. Global Land Cover 2015 raster data and terrain data (SRTM-DEM) of the study area have a spatial resolution of $30 \mathrm{~m}$, and they are available from the USGS database (https://earthexplorer.usgs.gov/).

\subsubsection{Data processing}

\section{Step 1. Smoothing processing of NDVI images}

A simplified least squares-fit convolution was proposed by Savitzky and Golay in order to smooth and compute derivatives of a set of consecutive spectrum values (Cao et al., 2018; Savitzky and Golay, 1964). The convolution can be recognized as a weighted moving average filter, with weight allocated as a polynomial of a certain form. We can apply the filter to any consecutive data when data points are at a fixed and uniform interval along the chosen abscissa, and the curves formed by graphing the points must be continuous and smooth. The long-term series GIMMS 3g NDVI and SPOT VGT NDVI just satisfy these conditions. The general equation of the simplified least-squares convolution for NDVI time-series smoothing is as follows:

$$
N D V I_{j}^{*}=\frac{\sum_{i=-m}^{i=m} C_{i} N D V I_{j+i}}{N},(1)
$$

Where $N D V I$ is the raw pixel value, $N D V I^{*}$ is the pixel smoothed value, $C_{i}$ is the coefficient for the $i^{\text {th }}$ NDVI value of the filter, and $N$ is the number of convoluting integers. It is equal to the smoothing window size $(2 \mathrm{~m}+1)$. The index $j$ is the running index of the original ordinate data table. The smoothing array (filter size) consists of $2 \mathrm{~m}+1$ points, where $m$ is the half-width of the smoothing window. The coefficients of a Savitzky- Golay filter $\left(C_{i}\right)$ are directly available from the latest version (Madden, 1978; Savitzky and Golay, 1964; Steinier, et al., 1974).

\section{Step 2. Co-registration of NDVI images}

The coordinates of the downloaded raw images showed some deviations because they were imaged with different sensors. In order to better analyze the data, especially the four types of images of the same area, we needed to make a geometric co-correction. In light of the large difference in the spatial resolution of images, the co-registration method based on image-to-image was performed for GIMMS 3g NDVI, VGT/PROBA-V, and Landsat NDVI. We selected the same geo-features, such as rivers, lakes, and mountains, to correct the images. The accuracy of this correction method is higher than the point-to-point method based on ground control points (GCP). Step 3. Sampling and statistics 
161

162

163

164

165

166

167

168

169

170

171

172

173

174

175

176

177

178

179

180

181

182

183

184

185

186

187

188

189

190

191

192

193

194

195

196

197

198

199

(1). Image sampling

Sampling is indispensable when finding the trend analysis of NDVI at the site scale. The location and the size of the sample especially will impact the results of NDVI trend analysis. Many factors were considered, such as the sample being an area of vegetation cover, and only using the single type of vegetation. Moreover, mixed pixels were eliminated for NDVI data with two different resolutions. Using the analysis above, we selected 15 representative sample sites, with a sample size of $8 \mathrm{~km} \times 8 \mathrm{~km}$ (GIMMS $3 g$ NDVI, $1 \times 1$ pixel. VGT $\backslash$ PROBA-V NDVI, $8 \times 8$ pixels). The 15 sample sites selected were Songpan (SP), Kangding (KD), Litang (LT), Jiuzhi (JZ), Derong (DR), Nangqian (NQ), Tongren (TR), Dege (Dege), Ruoergai (REG), Maerkang (MEK), Ruobei (RB), Zeku (ZK), Gongshan (GS), and Yanyuan (YY). The location and vegetation types of each site are shown in Table 2 and Fig. 2.

(2). Sample statistics

The basic principle of the sample statistics (Fig. 3) is that the calculation of pixel parameters was performed by setting a zonal window with a fixed size. The calculated parameters included the sum, mean, maximum, and minimum of the pixel values in the zonal window. The size of the zonal window was set to $8 \mathrm{~km} \times 8 \mathrm{~km}$ according to the lower resolution of the two different NDVI images in this study. The results were divided into three cases (possibilities) for GIMMS 3g images, using the mean statistics of a GIMMS $3 \mathrm{~g}$ image as an example. The formulations are as follows.

$$
\begin{gathered}
\text { Case }_{1} \text { : Mean }=V_{1} \text { or } V_{2} \text { or } V_{3} \text { or } V_{4},(2) \\
\text { Case }_{2}: \text { Mean }=\frac{V_{1}+V_{2}}{2} \text { or } \frac{V_{1}+V_{3}}{2} \text { or } \frac{V_{2}+V_{4}}{2} \text { or } \frac{V_{3}+V_{4}}{2}, \text { (3) } \\
\text { Case }_{3}: \text { Mean }=\frac{V_{1}+V_{2}+V_{3}+V_{4}}{4}, \text { (4) }
\end{gathered}
$$

Where $V$ is the pixel value of GIMMS $3 g$ NDVI images. According to this principle, the formula above was additionally followed for VGT/PROBA-V NDVI image statistics. Due to its higher resolution, more pixels were counted than in GIMMS NDVI images. Compared to the Point to Value Method (PVM), this method provides more accurate statistical results and reduces invalid values.

\subsection{Methodologies}

2.2.1. Detection of phenological change

Previous studies (Chandola et al., 2010; Chu et al., 2018; Gu et al., 2018; Tang et al., 2018) have used the dynamic threshold method to define the start of the growing season (SGS), the end of the growing season (EGS), and the length of the growing season (LGS). This method defines SGS and EGS as the moment when the pixel values increase and decrease, respectively, to a certain proportion of NDVI amplitude in one year. This method can avoid the mutual interference caused by different regional waterheat conditions, vegetation, and soil types in the fixed threshold method. The specific formulation is as follows:

$$
D_{S G S, E G S}=\left(N D V I_{\max }-N D V I_{\min }\right) \times C,(5)
$$

Where $N D V I_{\max }$ is the maximum value and $N D V I_{\min }$ is the minimum value of NDVI in one year. $C$ is the threshold ratio. According to previous studies (Yu et al., 2010; Jonsson et al., 2002) and the annual variation of vegetation in the study area, the SGS and EGS thresholds were set at $20 \%$ in the sample site. $D$ is a time judgment function where the time point is taken as EGS or SGS when NDVI increases or decreases to the threshold $C$. The time span from SGS to EGS is the LGS.

Peerj reviewing PDF | (2019:04:36681:2:2:REVIEW 24 Oct 2019) 
200

201

202

203

204

205

206

207

208

209

210

211

212

213

214

215

216

217

218

219

220

221

222

223

224

225

226

227

228

229

230

231

232

233

234

\subsubsection{Trend analysis of the NDVI change}

The stability and accuracy of the trend analysis method have been tested and it is widely used (Chu et al., 2018; Gu et al., 2018; Tang et al., 2018). This method was applied at a pixel scale in the period 19822018 to detect NDVI change and distribution. The formula is:

$$
\text { slope }=\frac{n \times \sum_{i=1}^{n}\left(i \times N D V I_{i}\right)-\sum_{i=1}^{n} i \sum_{i=1}^{n} N D V I_{i}}{n \times \sum_{i=1}^{n} i^{2}-\left(\sum_{i=1}^{n} i\right)^{2}}
$$

where $i$ is the number of the year, with the range 1 to $n$ (GIMMS NDVI, $n=34$; VGT NDVI, $n=20$ ). $N D V I_{i}$ represents the growing season NDVI of year $i$. The slope is the trend in NDVI from 1982 to 2018. A slope $>$ 0 indicates an increasing trend, while a slope $<0$ represents a decreasing trend during the study period. 2.2.3. Mann-Kendall trend test

The Mann-Kendall (M-K) trend test has been widely used as a non-parametric statistical test method (Gocic, et al., 2013; Yavuz, 2018). This test method does not require samples for normal distribution, and it has a high degree of quantification. This method is suitable to trend test time series data, especially the data of long-term series. The principles of the M-K trend test are as follows.

$$
S_{k}=\sum_{i=1}^{k} r_{i}, k=2,3 \cdots, n
$$

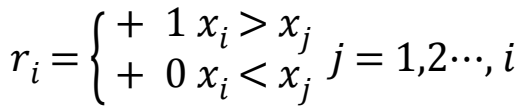

Where $n$ is the number of the sample, and $x$ is the time span. $s_{k}$ is the cumulative number of values at the time $i$, greater than those at the time $j$.

$$
\begin{gathered}
U F_{k}=\frac{\left|S_{k}-E\left(S_{k}\right)\right|}{\sqrt{\operatorname{var}\left(S_{k}\right)}, k=1,2 \cdots, n} \\
\left\{\begin{array}{c}
E\left(S_{k}\right)=\frac{k(k-1)}{4} \\
\operatorname{var}\left(S_{k}\right)=\frac{k(k-1)(2 k+5)}{72}, k=2,3, \cdots n
\end{array}\right.
\end{gathered}
$$

Where $U F_{k}$ is a statistic calculated by $x_{1}, x_{2}, \cdots x_{n}$. $E\left(S_{k}\right)$, and $\operatorname{var}\left(S_{k}\right)$ is the mean and variance of $S_{k}$. $U B_{k}=$ $-U F_{k}(k=n, n-1, \cdots, 1), U B_{1}=0 . a$ is the signification level. If $a=0.05$, then the $u_{0.05}= \pm 1.96$.

A $U F_{k}>0$ indicates an increasing trend, while a $U F_{k}<0$ represents a decreasing trend. When the critical line is exceeded $\left(u_{0.05}= \pm 1.96\right.$.), a significant upward or downward trend is shown.

\subsubsection{Bayesian trend test}

The traditional approach of trend analysis cannot detect the turning point for a set of data in a time series, and cannot estimate the change after it happens. The Bayesian method can overcome these difficulties. The Bayesian theorem constructed the probability distribution (posterior probability) function of the turning point of data change trends. The specific formula is:

$$
P(\theta \mid \text { data })=\frac{P(\text { data } \mid \theta) \times P(\theta)}{P(\text { data })},
$$

Where $P(\theta)$ denotes the prior probability distribution. $P(\theta \mid$ data $)$ is the posterior probability distribution, representing the confidence level of a turning point of change trends. $P$ (data) indicates the evidence; more importantly, it indicates the moment of data peak. For example, in a set of data in time series $\mathrm{X}=$ $\left\{\mathrm{x}_{1982}, \mathrm{x}_{1983}, \mathrm{x}_{1984} \cdots \mathrm{x}_{2015}\right\}$, how do the data change? We would need to calculate the moment and the probability of the turning point occurring when the trend changes. We referred to previous studies (Hèou, et al., 2017; Peter, et al., 2018; Zhao, et al., 2019; John, et al., 2015) to calculate the moment and 
235

236

237

238

239

240

241

242

243

244

245

246

247

248

249

250

251

252

253

254

255

256

257

258

259

260

261

262

263

264

265

266

267

268

269

270

271

272

273

274

probability of the turning point occurring (Fig. 4). The combination of the Bayesian approach and M-K trend analysis can improve the accuracy of trend analysis, and can validate $\mathrm{M}-\mathrm{K}$ trend analysis. The flowchart of methodology used in this study is shown in Fig. 5.

\section{Results}

\subsection{GIMMS 3g NDVI-based vegetation dynamic trends from 1982 to 2015}

\subsubsection{Phenological trends of vegetation}

The dynamic threshold method was used to detect the phenological changes of three ecosystems from 1982 to 2015. The trend of phenology change (Fig. 6A, B, C, G, H, and I) and the M-K trend test (Fig. 6D, E, F, J, K, and L) are shown in Fig. 6. In the forest ecosystem (Fig. 6A and Fig. 6E), the SGS change trend rose (slope $=10.08$ days/decade, $U F<0$, Sig. $=0.05$ ), and then began to fall (slope $=2.06$ days $/$ decade, $U F>0$, Sig. $=0.05$ ), showing overall trending delays (slope $=0.66$ days/decade). The EGS showed a slight decline from 1982 to 2015 (slope $=0.15$ day/decade), although it began to advance after 1998 (slope $=0.89$ day/decade). It was calculated that the LGS decreased by 0.51 days/ decade based on the SGS and EGS during the study period. The curves of the SGS and EGS for grassland ecosystems are shown in Fig. 6C and Fig. 6I. The SGS of the grassland ecosystem was accelerated by 0.64 days/decade, and the EGS was delayed by 0.46 days/ decade. Accordingly, the LGS was prolonged by 1.1 days/decade from 1982 to 2015 . The variation trend of SGS in the grassland ecosystem was consistent with that of the forest ecosystem. The year 1998 was the turning point of the curve, and after that year, the SGS curve showed trending delays (slope $=2.68$ days/ decade). For the farmland ecosystem (Fig. 6A and Fig. 6G), the trend of change was consistent with that of the grassland and forest ecosystem, except for the change rate of SGS. From 1982 to 2015, the SGS trend was accelerated by 2.98 days/decade, and the EGS was delayed by 1.07 days/decade. Due to the acceleration of the SGS and the delay of the EGS, the LGS was prolonged by 8.74 days/decade (1982-2015).

\subsubsection{Spatial dynamics of vegetation}

We calculated the trend and spatial distribution of NDVI changes across different seasons from 1982 to 2015 (Fig. 7). In spring (Fig. 7A), the trend range of NDVI change was from $-0.0679 /$ decade to $0.0693 /$ decade. Vegetation increased most in the area with a percentage of $82.1 \%$, and were mainly distributed in SP, GS, YY, REG and MEK. The needle-leaf deciduous forest showed vigorous activity in SP, GS, and YY, and the vegetation coverage of swamp and plain grassland also experienced an upward trend in REG and MEK. The vegetation dynamics showed a weak upward trend in DR, JZ, and NQ. The slope was 0.005/decade to 0.013/decade in the alpine and subalpine meadows distributed in this area. In addition, vegetation deterioration had occurred in regions of the EMQTP, such as the west of ZK and DR. The west of DR was especially affected, as it is a desert grassland with low vegetation coverage. As shown in Fig. 7B, summer vegetation experienced great degradation with more than $51.5 \%$ of the area showing a downward trend. In particular, the south section of the study area had a slope of 0.08 / decade. The proportion of the vegetation increase area was $71.7 \%$, and was mainly distributed in NQ and DG regions due to the degeneration of desert grassland. The vegetation dynamic in autumn (Fig. 7C) was basically consistent with the mean trend of the full growing season (Fig. 7D). The area of NDVI increase accounted for $75.1 \%$ in the full growing season. The difference between autumn and the growing season is only shown in the slope rate of NDVI increase and decrease. In the growing season, the slope was -

Peer] reviewing PDF | (2019:04:36681:2:2:REVIEW 24 Oct 2019) 
275

276

277

278

279

280

281

282

283

284

285

286

287

288

289

290

291

292

293

294

295

296

297

298

299

300

301

302

303

304

305

306

307

308

309

310

311

312

313

314

315

0.0394/decade to $0.0486 /$ decade. The maximum value appeared in RE, the south of SP, and the central region of the study area. Through the analysis of vegetation dynamics across different seasons, we found that the decrease of NDVI was mainly distributed in the western DR region and near the dry valley in the south of the study area. The areas with obvious increases were distributed in the east section of the study area. Because the EMQTP is a sub area of QTP, the spatial distribution of vegetation change provided a quantitative value that could be compared with Peng's results (Fig. 7 of Peng's work). Although the time ranges of NDVI were greatly different (1982-2003 and 1982-2015), they can better reflect the decreasing trend of vegetation in the arid valley.

\subsection{VGT\PROBA-V NDVI-based vegetation dynamic trend from 1999 to 2018}

\subsubsection{Phenological trends of vegetation}

We used the VGT $\backslash$ PROBA-V NDVI with a fine resolution to calculate phenological trends. The change detection of the SGS and EGS were performed on the most recent 19 years. The trend of SGS change for the forest ecosystem showed delay (slope $=0.66$ days $/$ decade, $-1.96<$ Sig. $<1.96$ ), and the EGS showed a slight advanced trend (slope $=2.99$ day/decade, UF $<0,-1.96<$ Sig. $<1.96$ ). Thus, it was calculated that the LGS decreased by 3.65 days/decade during this period. The SGS and EGS curves for the grassland ecosystem are shown in Fig. 8C and Fig. 8G. The SGS of the grassland ecosystem was delayed by 0.92 days/decade, and the EGS was delayed by 1.05 days/ decade. Accordingly, the LGS was prolonged by 0.03 days/decade. Compared with the forest ecosystem, the grassland ecosystem showed an obvious uptrend. In the farmland ecosystem (Fig. 8A and Fig. 8D), the SGS was delayed by 5.76 days/decade and the EGS was delayed by 0.67 days/decade. Due to the delays of the SGS and the EGS, the LGS was shortened by 5.09 days/decade.

\subsubsection{Spatial dynamics of vegetation}

In the most recent 19 years (1999-2018), NDVI showed a decreasing trend with the area accounting for $63.4 \%$ in spring (Fig. 9A). Most was grassland cover area with a slope less than 0.004/decade. Moreover, NDVI had decreased significantly in the eastern and southern dry valleys of the study area. This area was covered by forest, especially obvious in the east of REG, south MEK, and the northwestern section of KD. The areas of NDVI increase in summer (Fig. 9B), autumn (Fig. 9C), and the growing season (Fig. 9D) were $71.8 \%, 60.9 \%$ and $65.4 \%$, respectively. The slopes of NDVI increase and decrease were similar and the distribution area was roughly consistent. Compared with the spatial distribution of NDVI changes from 1982 to 2015, a large area near REG showed some obvious differences. This area was covered by alpine and sub-alpine meadows, and NDVI showed a downward trend with a slope of about 0.005/decade, especially in the summer (Fig. 9B). This indicated that vegetation degradation in the NEG region has been more noticeable in the last 19 years, and more attention should be paid to the changes in the ecological environment of this area.

\subsection{Crossing analysis of the vegetation dynamic from 1999 to 2015}

We used GIMMS 3g NDVI and VGT $\backslash$ PROBA-V NDVI to perform trend analysis across different seasons between 1999 and 2015. The vegetation dynamics reflected the change trend and spatial distribution of vegetation. We divided the vegetation dynamics into three categories (decrease, weak change, and increase) according to the trend ratio of vegetation, ultimately creating the vegetation dynamic map (Fig. 10). GIMMS 3g NDVI's general change trend was basically consistent with the results that used VGT $\backslash$ PROBA-V NDVI. Evidently, the spatial distribution of vegetation dynamics using 
VGT $\backslash$ PROBA-V NDVI appeared finer than the results using GIMMS 3g NDVI. Vegetation degradation areas were mainly distributed in the REG grassland region and the arid valley regions of the Jinsha River and Yalong River. The areas with high vegetation activity appeared in the southeast of MEK and the south section of the study area, which included GS and YY.

In order to more deeply analyze the vegetation dynamic, we calculated the trend of each vegetation type at a site scale (Fig. 11). As can be seen in Fig. $11 \mathrm{~A}-\mathrm{H}$, most of the vegetation showed an upward trend, while the AM (DR, NQ and JZ site) showed a downward trend. This result was consistent with the vegetation dynamics shown in Fig. $11 \mathrm{~A}$ and $\mathrm{B}$. In addition, there were some differences between the two data analysis results, such as the change trend of TM vegetation, caused by the spatial resolution of the two datasets. In autumn, WL (MEK site), AM (DR, NQ and JZ site), and PG (REG site) showed a downward trend with different slopes. The downward trend of PG (REG site) was the most significant, and was also reflected in the vegetation dynamic distribution map (Fig.10C and G). For the full growing season, the change trend of the seven cover types experienced an upward trend based on two NDVI image products. Compared with Peng's research results (Fig. 6 of Peng's work), the analysis at the site scale objectively reflects the NDVI change trend of the local area. It represents the change trend of various vegetation changing with the environment, rather than just a simple average of the different regions.

\section{Discussion}

\subsection{Validation of the phenological changes}

We used the M-K method to achieve the general trend of phenological changes in sub section 3.3.1. In order to better detect the change trend across different phases, Bayesian trend analysis was performed to obtain continuous probability and the turning points of the trend change from 1982 to 2015. The results of our calculations are shown in Fig. 12. In regard to the change trend of the SGS, the turning point was in 1998 and the probability of occurrence was more than 0.5 . The turning point of the change trend in forests (Fig.12 B) was consistent with the M-K analysis results (Fig. 6E). Moreover, the change trend of the SGS was divided into two phases: before and after the turning point in 1998. Before 1998, SGS showed a downward trend, and the value of beta occurred continuously. SGS showed an upward change trend after the turning point. However, there was neither an obvious change trend nor turning point (the higher probability) for the EGS.

We selected the SGS (A-1982, B-1998, and C-2015) and EGS images of the VIP grid (D-1982, E-1998, and F-2015) to validate the phenology change from 1982 to 2015. SGS and EGS images of VIP in 1982, 1998, and 2015 can be seen in Fig. 13. The location of the sample site (Table 1) was used to extract the phenology change of vegetation based on VIP images in this study. Then the extracted data were used to validate the phenology changes of the SGS and EGS. The validation results are shown in Fig. 14. The overall trend of phenology change of VIP was consistent with that of GIMMS. In the analysis of section 3.1, we found that the phenology change showed an advanced trend before 1998, and then appeared to delay until 2015. This turning point of phenology change was also seen in the SGS change of VIP V4.

We also analyzed previous studies on phenology change in this area and nearby regions. Before 1998, the turning point of phenology change, the SGS showed an obvious advanced trend with an average slope of 10 days/decade (UF $<0,-1.96<$ Sig. $<1.96$ ) for various vegetation ecosystems. This was basically consistent with the results of other relevant research, which found that the slope of SGS ranged 
356

357

358

359

360

361

362

363

364

365

366

367

368

369

370

371

372

373

374

375

376

377

378

379

380

381

382

383

384

385

386

\section{7}

388

389

390

391

392

393

394

from 3.5 to 10.2 days/decade using various method and sub-areas (Zhang et al.,2013; Shen et al., 2014; Piao et al., 2011; Kong et al., 2017). Many scholars have found 1998 as the approximate turning point of SGS in the QTP, which is highly consistent with the result of this study (Piao et al., 2011; Shen et al., 2016). The SGS showed a delay trend after 1998, and the delays calculated by GIMMS $3 g$ and VGT NDVI were 1.8 days/decade and 0.7 days/decade, respectively, but the significance (Sig.) was greater than 0.05 in the EMQTP. Currently, the trend of SGS change in the QTP after 1998 is a controversial topic (Zhang et al, 2013; Yu et al., 2010; Shen et al., 2013). In this study, the average EGS of vegetation ecosystem was delayed by 1 day/decade between 1982 and 2018. This is consistent with Che's finding (Che et al., 2014) that the phenological change trend of the QTP at the end of the growing season was not guaranteed (slope $=0.96$ day/decade).

\subsection{Validation of the vegetation dynamics}

The analysis of section 3.2 and 3.3 show that vegetation degradation has been obvious in the REG area, especially in the last 20 years. Thus, the validation of vegetation dynamics in this area was performed based on the Landsat NDVI. Because the most significant degradation appears in autumn, we used autumn Landsat NDVI to validate the vegetation dynamics. Because of the quality (the cloud was less than $5 \%$ ) of the Landsat orthophoto, the 10 scenes selected were mainly from September and October, and the time difference was less than a week. Moreover, we designed five sites to make the results of the validation more intuitive. The validation results can be seen in Fig. 15. Although the resolutions of VGT $\backslash$ PROBA-V NDVI $(1 \mathrm{~km})$ and Landsat NDVI $(30 \mathrm{~m})$ were different, the general vegetation dynamic trends were fundamentally consistent (Fig. 15A and Fig. 15B). In particular, the validation sites showed significant downward trends, indicating our previous calculations (sub-section 3.2) of vegetation degradation were correct. In the circle image (the zoom view of the validation site), the vegetation dynamic is due to the degradation of the alpine meadow (Site 1 and Site 2). Additionally, human activities, such as changing farmland area (Site 4) and the expansion of residential areas (Site 3 and Site 5) also have an impact on vegetation degradation. Previous studies have revealed the degradation of alpine wetland meadows in the REG area, including the shrinkage of meadows (Li et al., 2015), ecological degradation (Shen et al., 2019), and an increase of cultivated land (Rong et al., 2010). The validation results in section 3 showed that vegetation dynamics and change trends are reasonable and credible. Other previous works (Chen, 2018; Bian et al., 2017) have also proven the vegetation degradation in REG area, and that the reason for vegetation degradation in the dry valley near the southern section isrelated to climate change (Wang, et al., 2018).

\section{Conclusions}

We combined the high spatial resolution of Landsat NDVI with the long temporal span of GIMMS $3 \mathrm{~g}$ NDVI and VGT/PROBA-V NDVI to establish a 37-year record of vegetation dynamics in the EMQTP at $1 \mathrm{~km}$ and $8 \mathrm{~km}$ spatial resolution. Our research focused on the phenological change of vegetation ecosystems, the trends of change, and fluctuation characteristics for various vegetation types in this sensitive area responding to global environmental change. The acquired findings on vegetation dynamics in the EMQTP, particularly in phenological changes and fluctuation characteristics for various vegetation types, can be summarized as follows:

Peerj reviewing PDF | (2019:04:36681:2:2:REVIEW 24 Oct 2019) 
(1). The SGS of vegetation ecosystems advanced from 1982 to 1998, and then experienced trending delays until 2018. The average advanced slope and delayed slope were 11.51 days/decade and 3.86 days/decade, respectively. The LGS of the vegetation ecosystem was prolonged with an average value of 4.24 days/decade, and the LGS of the farmland ecosystem showed the most significant prolongation trend.

(2). In the full growing season, the slope of the vegetation index (NDVI) ranged from $-0.039 /$ decade to 0.049 /decade. Most of this area showed an upward trend with a percentage of $75.1 \%$. When compared with the forest ecosystem, the grassland ecosystem showed weaker activity and the appearance of degradation, particularly in spring and autumn.

(3). In the most recent 19 years, vegetation has degenerated in REG and the arid valley region of the Jinsha River and Yalong River. This finding has also been confirmed by Landsat NDVI. Vegetation degradation is due to the shrinking of alpine meadows and the impact of human activities, which include the change of farmland area and the expansion of residential areas.

\section{Acknowledgements}

We thank VITO, ECOCAST, Global Inventory Modeling and Mapping Studies (GIMMS), and WESTDC for the freely downloadable VGT $\backslash$ PROBA-V and GIMMS 3g NDVI datasets, SRTM DEM, and vegetation vector map products, respectively. We would also like to thank the anonymous reviewers for their constructive and detailed comments.

\section{REFERENCES}

A. de la Casa, G. Ovando, L. Bressanini, J. Martinez, G. Diaz, C. Miranda, 2018. Soybean crop coverage estimation from NDVI images with different spatial resolution to evaluate yield variability in a plot. ISPRS J. Photogram. 146: 531-547. DOI 10.1016/j.isprsjprs.2018.10.018.

Amelie, V., David R.J., Francis, R., Jean, P.Q., Qiu, J.M., Qian, W., Li, T.Y., Nadine, B., Michael, C., Pierre, D., Kenichi, T., Weidmann, J.C., Patric, G., 2009. Modelling and spatial discrimination of small mammal assemblages: An example from western Sichuan (China) Ecological Modelling, 220, 1218-1231. DOI 10.1016/j.ecolmodel.2009.02.019.

Bian, J.H., Li, A.N., Zhang, Z.J., 2017. Monitoring fractional green vegetation cover dynamics over a seasonally inundated alpine wetland using dense time series $\mathrm{HJ}-1 \mathrm{~A} / \mathrm{B}$ constellation images and an adaptive endmember selection LSMM model. Remote Sens. Environ. 197: 98-114. DOI 0.1016/j.rse.2017.05.031.

Cao, R.Y., Chen, Y., Shen, M.G., Chen, J., Wang, W.Y., 2018. A simple method to improve the quality of NDVI time-series data byintegrating spatiotemporal information with the Savitzky-Golay filter. Remote Sensing of Environment,217,244-257. DOI 10.1016/j.rse.2018.08.022.

Casa, A., Ovando, G., Bressanini, L., Martinez, J., Diaz, G., Miranda, G., 2018. Soybean crop coverage estimation from NDVI images with different spatial resolution to evaluate yield variability in a plot. ISPRS journal of photogrammetry and remote sensing, 146,531-547. DOI 10.1016/j.isprsjprs.2018.10.018. 
432

433

434

435

436

437

438

439

440

441

442

443

444

445

446

447

448

449

450

451

452

453

454

455

456

457

458

459

460

461

462

463

464

465

466

467

468

469

470

471

Chandola, V., Hui, D., Gu, L., Bhaduri, B. and Vatsavai, R.R., 2010. Using time series segmentation for deriving vegetation phenology indices from MODIS NDVI data, Data Mining Workshops (ICDMW), 2010 IEEE International Conference on. IEEE, Sydney, Australia, 202-208.

Chavez, R.O., Moreira-Munoz, A., Galleguillos, M., Olea, M., Aguayo, J., Latin, A., Aguilera-Betti, I., Munoz, A.A., Manriquez, H., 2019. Int J Appl Earth Obs Geoinformation, 76,193-203. DOI 10.1016/j.jag.2018.11.013.

Che, M., Chen, B., Innes J L., 2014. Spatial and temporal variations in the end date of the vegetation growing season throughout the Qinghai-Tibetan Plateau from 1982 to 2011. Agr. Forest Meteorol. 189/190: 81-90. DOI 10.1016/j.agrformet.2014.01.004.

Chen, J. L., 2018. Analysis on vegetation change and driving factors in the alpine plateau of REG. Sichuan Normal University, Master Dissertation. 1-63.

Chris, W., 2015. Psychology journal bans P values. Nature, 7541 (519). DOI:10.1038/519009f.

Chu, H.S., Sergey Venevsky, Wu, C., Wang, M.H., 2018. NDVI-based vegetation dynamics and its response to climate changes at Amur-Heilongiiang River Basin from 1982 to 2015. Sci. Total Environ. 650: 2051-2062. DOI 10.1016/j.scitotenv.2018.09.115.

Du, J.Q., Shu, J.M., Yin, J.Q., Yuan, X.J., Ahati Jiaerheng, Xiong, S.S., He, P., Liu, W.L., 2015. Analysis on spatio-temporal trends and drivers in vegetation growth during recent decades in Xinjiang, China. Int. J. App. Earth Obs. 38: 216-228. DOI 10.1016/j.jag.2015.01.006.

Fei P., Xian, X., You, Q.G., Huang, G.H., Dong, S.Y., Liao, J., Duan, H.C., Atsushi, T., Wang, T., 2018. Changes of soil properties regulate the soil organic carbon loss with grassland degradation on the Qinghai-Tibet Plateau. Ecological Indicators 93, 572-580. DOI 10.1016/j.ecolind.2018.05.047.

Florian Detsch, Insa Otte, Tim Appelhans, Andreas Hemp, Thomas Nauss, 2016. Seasonal and longterm vegetation dynamics from 1-km GIMMS-based NDVI time series at Mt. Kilimanjaro, Tanzania. Remote Sens. Environ. 178: 70-83. DOI 10.1016/j.rse.2016.03.007.

Gocic M., Trajkovic S., 2013. Analysis of changes in meteorological variables using Mann-Kendall and Sen's slope estimator statistical tests in Serbia. Global and Planetary Change,100, 72-182. DOI 10.1016/j.gloplacha.2012.10.014.

Gu, Z.J., Duan, X.W., Shi, Y.D., Li, Y., Pan, X., 2018. Spatiotemporal variation in vegetation coverage and its response to climatic factors in the Red River Basin, China. Ecol. Indic. 93:53-64. DOI 10.1016/j.ecolind.2018.04.033.

Hèou M. B., Benjamin R., Jörg H., Kodjovi S. E., Abel A., Kpérkouma W. 2017. Bayesian trend analysis in annual rainfall total, duration and maximum in the Kara River basin (West Africa). Journal of Hydrology: Regional Studies 13, 255-273. DOI 10.1016/j.ejrh.2017.08.009.

Holben, B.N., 1986. Characteristics of maximum-value composite images from temporal AVHRR data. Int. J. Remote Sens. 7: 1417-1434. DOI 10.1080/01431168608948945.

Hu, C.J., Fu, B.J., Liu, G.H., Jin, T.T., Guo, L., 2010. Vegetation patterns influence on soil microbial biomass and functional diversity in a hilly area of the Loess Plateau, China. J. Soil Sediment. 10(6): 1082-1091. DOI 10.1007/s11368-010-0209-3.

IPCC, 2014. The Synthesis Report (SYR) of the IPCC Fifth. Available at https://archive.ipcc.ch/report/ar5/syr/. 
472

473

474

475

476

477

478

479

480

481

482

483

484

485

486

487

488

489

490

491

492

493

494

495

496

497

498

499

500

501

502

503

504

505

506

507

508

509

510

Ji L, Gallo K, Eidenshink J C. 2008. Agreement evaluation of AVHRR and MODIS 16-day composite NDVI datasets [J]. International Journal of Remote Sensing, 29(16): 4839-4861

John S., Thomas V.W., Christopher F., 2015. Probabilistic programming in Python using PyMC3. Peer J, DOI 10.7717/peerj-cs.55.

Jonsson, P. and Eklundh, L., 2002. Seasonality extraction by function fitting to time-series of satellite sensor data. IEEE T. Geo. sci. Remote. 40(8):1824-1832. DOI: 10.1109/TGRS.2002.802519.

Kelly, M., Tuxen, K.A., Stralberg, D., 2011. Mapping changes to vegetation pattern in a restoring wetland: finding pattern metrics that are consistent across spatial scale and time. Ecol. Indic. 11(2): 263-273. DOI 10.1016/j.ecolind.2010.05.003.

Kong, D.D., Zhang, Q., Huang, W.L, Gu, X.H., 2017. Vegetation phenology change in Tibetan Plateau from 1982 to 2013 and its related meteorological factors. Acta Geogr. Sin. 72(1): 39-52.

Li G.Y., Jiang, C., Cheng, T., Bai J., 2019. Grazing alters the phenology of alpine steppe by changing the surface physical environment on the northeast Qinghai-Tibet Plateau, China. Journal of Environmental Management, 248,109257. DOI 10.1016/j.jenvman.2019.07028.

Li, H., Renssen, M., Roche, M., 2019. Global vegetation distribution driving factors in two dynamic global vegetation models of contrasting complexities. Global and Planetary Change, 180,51-56. DOI 10.1016/j.gloplacha.2019.05.009.

Li, L.H., Zhang, Y.L., Wu, J.S., Li, S.C., Zhang, B.H., Zu, J.X., Zhang, H.M., Ding, M.J., Paudel, B., 2019. Increasing sensitivity of alpine grasslands to climate variability along an elevational gradient on the Qinghai-Tibet Plateau. Science of the total environment, 678, 21-29. DOI 10.1016/j.scitotenv.2019.04.399.

Li, Y.F., Li, Z.W., Wang, Z.Y., Wang, W.L., Ji, Y.H., Tian, S.M., 2017. Impacts of artificially planted vegetation on the ecological restoration of movable sand dunes in the Mugetan Desert, northeastern Qinghai-Tibet Plateau. Int. J. Sediment Res. 32(2):277-287. DOI 10.1016/j.ijsrc.2017.02.003.

Li, Z.W., Wang, Z.Y., Brierley, G., Nicoll, T. Pan, B.Z., Li, Y.F, 2015. Shrinkage of the Ruoergai Swamp and changes to landscape connectivity, Qinghai-Tibet Plateau. Catena, 126, 155163. DOI 10.1016/j.catena.2014.10.035.

Liu, D., Cao, C.X., Olena Dubovyk, T, R., C, W., Z, Q.F., Zhao, Y.J., Gunter Menz, 2017. Using fuzzy analytic hierarchy process for spatio-temporal analysis of eco-environmental vulnerability change during 1990-2010 in Sanjiangyuan region, China. Ecol. Indic. 73: 612-625. DOI 10.1016/j.ecolind.2016.08.031.

Liu, Z, J., Wu, C. Y., Liu, Y. S., Wang, X. Y., Fang, B., Yuan, W. P., Ge, Q. S., 2017. Spring green-up date derived from GIMMS3g and SPOT-VGT NDVI of winter wheat cropland in the North China Plain. ISPRS J. Photogramm. 130: 81-91. DOI 10.1016/j.isprsjprs.2017.05.015.

Madden, H. 1978. Comments on the Savitzky - Golay convolution method for least-squares fit smoothing and differentiation of digital data. Analytical Chemistry, 50(9): 1383 - 1386.

NASA-NEX, 2019. Available at https://nex.nasa.gov/nex/projects/1349/

Peng, J., Liu, Z.H., Liu, Y.H., Wu, J.S., Han, Y.A., 2012.Trend analysis of vegetation dynamics in QinghaiTibet Plateau using Hurst Exponent. Ecol. Indic. 14(1): 28-39. DOI 10.1016/j.ecolind.2011.08.011. 
511

512

513

514

515

516

517

518

519

520

521

522

523

524

525

526

527

528

529

530

531

532

533

534

535

536

537

538

539

540

541

542

543

544

545

546

547

548

549

Peter P., Bradley R., Dennis P. Watson, P. H., Marion S. 2018. Greened Fentanyl related overdose in Indianapolis: Estimating trends using multilevel Bayesian models. Addictive Behaviors 86, 4-10. DOI 10.1016/j.addbeh.2018.03.010.

Piao, S., Fang, J., 2003. Seasonal changes in vegetation activity in response to climate changes in China between 1982 and 1999. Acta Geogr. Sin. 58(1), 119-125.

Piao, S.L., Cui, M.D., Chen, A.P., Wang, X.H., 2011. Altitude and temperature dependence of change in the spring vegetation green- up date from 1982 to 2006 in the Qinghai-Xizang Plateau. Agr. Forest Meteorol. 151(12): 1599-1608. DOI 10.1016/j.agrformet.2011.06.016.

PROBA-V Products User Manual-Version: 3.01, 2018.

Rong, X.D., Bo, T., Kun, T., Yang, Y., 2010. Landscape patterns and their changes in Sichuan Ruoergai Wetland National Nature Reserve. Acta Ecological Sinica, 30, 27-32. DOI 10.1016/j.chnaes.2009.12.005

Savitzky, A., \& Golay, M. J. E. 1964. Smoothing and differentiation of data by simplified least squares procedures. Analytical Chemistry, 36: 1627 - 1639.

Shen, G., Yang, X.C., Jin, Y.X., Xu, B., Zhou, Q.B., 2019. Remote sensing and evaluation of the wetland ecological degradation process of the Zoige Plateau Wetland in China. DOI 10.1016/j.ecolind.2019.04.063.

Shen, M., Piao, S., Dorji T., 2016. Plant phenological responses to climate change on the Tibetan Plateau: Research status and challenges. Natl. Sci. Rev. 2(4): 454-467. DOI 10.1093/nsr/nwv058.

Shen, M., Sun, Z., Wang, S., 2013. No evidence of continuously advanced green-up dates in the Tibetan Plateau over the last decade. P. Natl. Acad. Sci. USA. 110(26): E2329. DOI 10.1073/pnas.1304625110.

Shen, M.G., Zhang, G.X., Cong, N., Wang, S.P., 2014. Increasing altitudinal gradient of spring vegetation phenology during the last decade on the Qinghai-Tibetan Plateau. Agr. Forest Meteorol. 189-190: 7180. DOI 10.1016/j.agrformet.2014.01.003.

Steinier, J., Termonia, Y., \& Deltour, J. 1972. Comments on smoothing and differentiation of data by simplified least squares procedure. Analytical Chemistry, 44(11): 1906 - 1909.

Tang, Z.G., Ma, J.H., Peng, H.H., Wang, S.H., Wei, J.F., 2018. Spatiotemporal changes of vegetation and their responses to temperature and precipitation in upper Shiyang river basin. Adv. Space Res. 60(15): 969-979. DOI 10.1016/j.asr.2017.05.033.

Torrence C, Compo G P., 1998. A practical guide to wavelet analysis. B. Am. Meteorol. Soc. 79(1), 61-68

Tucker, C.J., 1979. Red and photographic infrared linear combinations for monitoring vegetation. Remote Sens. Environ. 8(2): 127-150. DOI 10.1016/0034-4257(79)90013-0.

Vegetation Index and Phenology Lab., The University of Arizona (VIP Lab.), 2011. Available at https://vip.arizona.edu.

VITO, 2018. SPOT vegetation FAQ (frequently asked questions). Available at VITO, 2018. SPOT vegetation FAQ (frequently asked questions)

Wang, X., Yao, Y.F., Alexandra H. Wortley., 2018.Vegetation responses to the warming at the Younger Dryas-Holocene transition in the Hengduan Mountains, southwestern China. Quaternary Sci. Rev. 192: 236-248. DOI 10.1016/j.quascirev.2018.06.007.

Peer] reviewing PDF | (2019:04:36681:2:2:REVIEW 24 Oct 2019) 
550

551

552

553

554

555

556

557

558

559

560

561

562

563

564

565

566

567

Wu, C.Y., Peng, D.L, Kamel Soudani, Lukas Siebicke, 2017. Land surface phenology derived from normalized difference vegetation index (NDVI) at global FLUXNET sites. Agr. Forest Meteorol. 233: 171-182. DOI 10.1016/j.agrformet.2016.11.193.

Yang, Y., Piao, S., 2006. Variations in grassland vegetation cover in relation to climatic factors on the Tibetan Plateau. J. Plant Ecol-China. 30(1), 1-8 .

Yavuz Selim Guclu, 2018. Multiple sen-innovative trend analyses and partial Mann-Kendall test. Journal of Hydrology,566, 685-704. DOI 10.1016/j.jhydrol.2018.09.034.

Yu, H., Luedeling, E. and Xu, J., 2010. Winter and spring warming result in delayed spring phenology on the Tibet plateau. P. Natl. Acad. Sci. USA. 107(51): 22151-22156. DOI 10.1073/pnas.1012490107.

Zhang, G., Zhang, Y., Dong, J., 2013. Green-up dates in the Tibetan Plateau have continuously advanced from 1982 to 2011. P. Natl. Acad. Sci. USA. 110(11): 4309-4314. DOI 10.1073/pnas.1210423110.

Zhao, K.G., Michael A. Wulder, Hu T, Ryan B., Wu, Q.S., Qin, H.M., Li, Y., Elizabeth T, Bani M, Zhang, X.S., Molly B., 2019. Detecting change-point, trend, and seasonality in satellite time series data to track abrupt changes and nonlinear dynamics: A Bayesian ensemble algorithm. Remote sensing of Environment, 232,111181 DOI 10.1016/j.rse.2019.04.034.

Zheng, Y.T., Han, J.C., Huang, Y.F., Steven R. Fassnacht, Xie, S., Enze Lv, Chen, M., 2017. Vegetation response to climate conditions based on NDVI simulations using stepwise cluster analysis for the Three-River Headwaters region of China. Ecol. Indic. 92: 18-29. DOI 0.1016/j.ecolind.2017.06.040. 
Figure 1

Geographical location (A), land use and land cover (B, GLC2015), and the digital elevation model (C, STRM-30m) of the study area.

A) Geographical location. (B) Land use and land cover (GLC 2015). (C) Digital elevation model (STRM 30m)

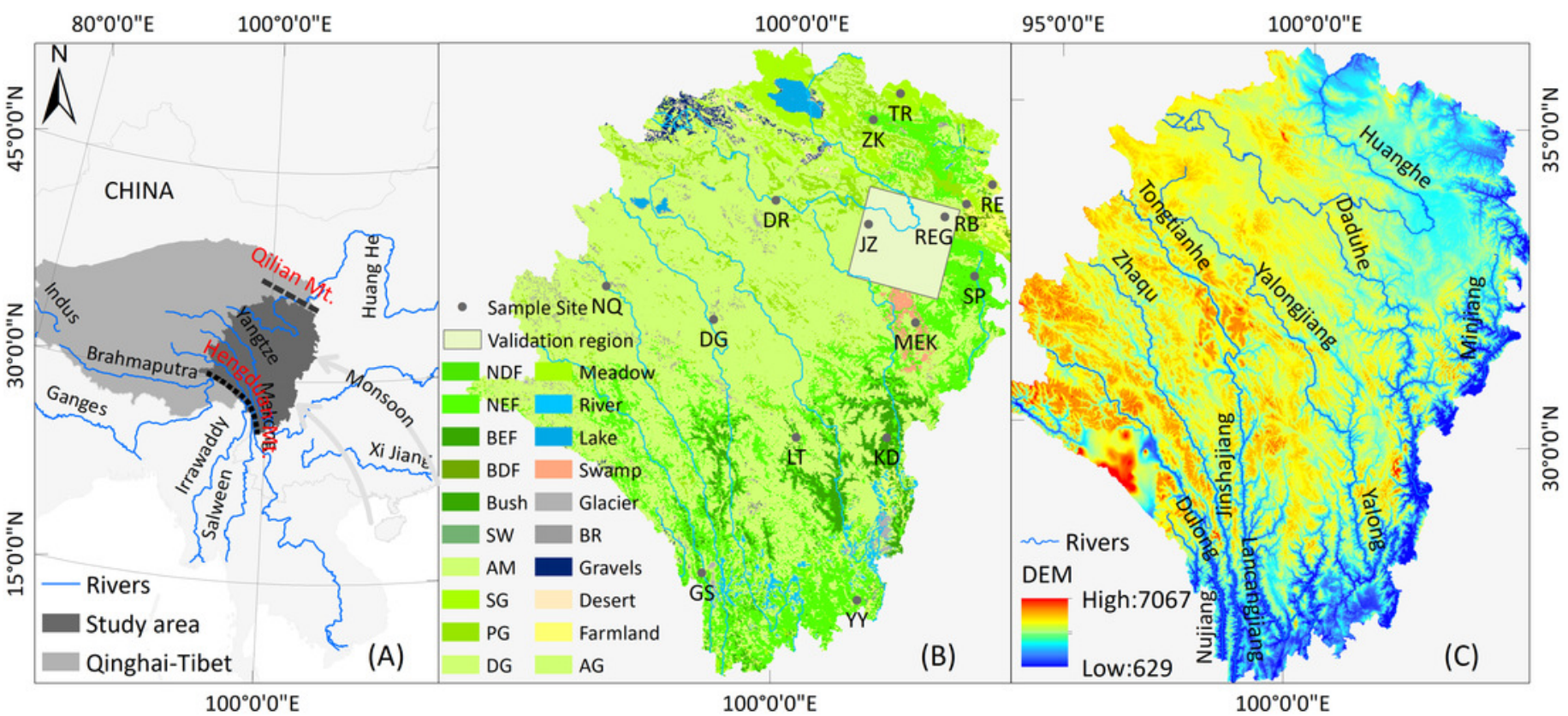


Figure 2

Vegetation cover types of sample site in study area.

(A) NQ, (B) DG, (C) REG, (D) TR, (E) GS, (F) YY, (G) LT, and (H) SP.

Note: The photographer is Haijun Wang.
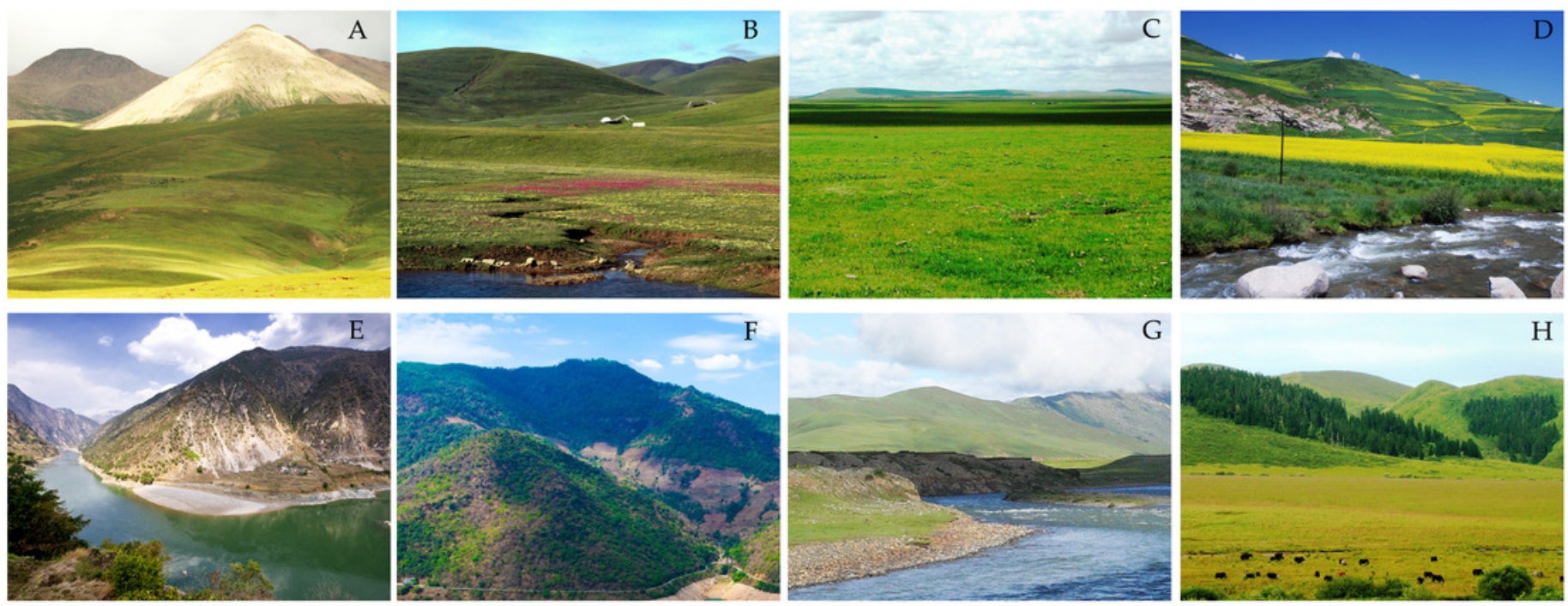

G
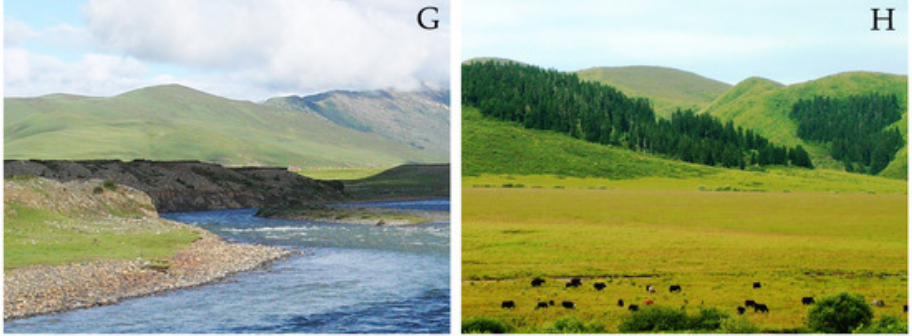
Figure 3

Schematic diagram of sample statistics.

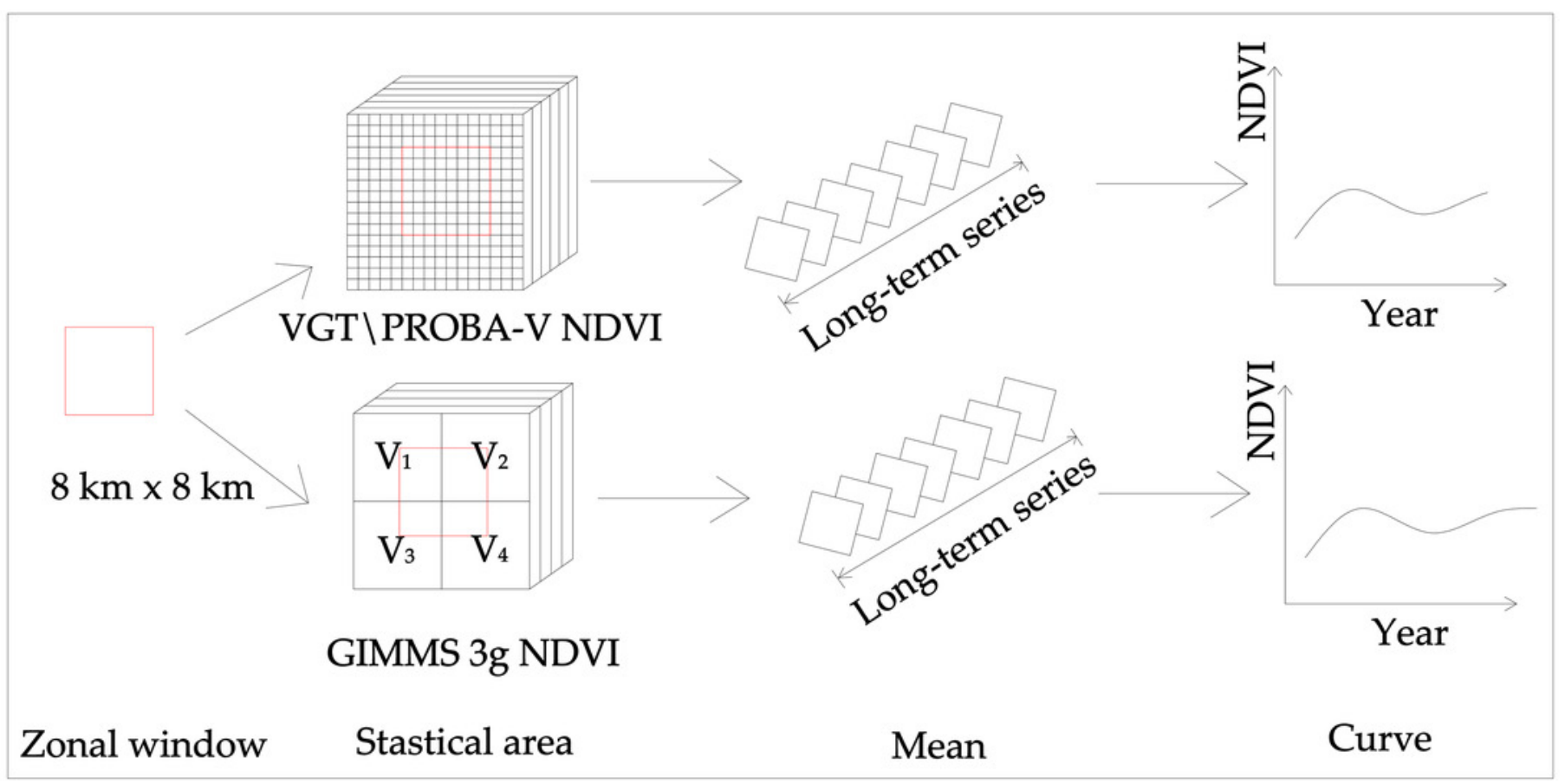


Figure 4

The trend and the confidence level of NDVI change based on the Bayesian method. Note: Beta $(\beta)$ represents the continuous probability of trend change.

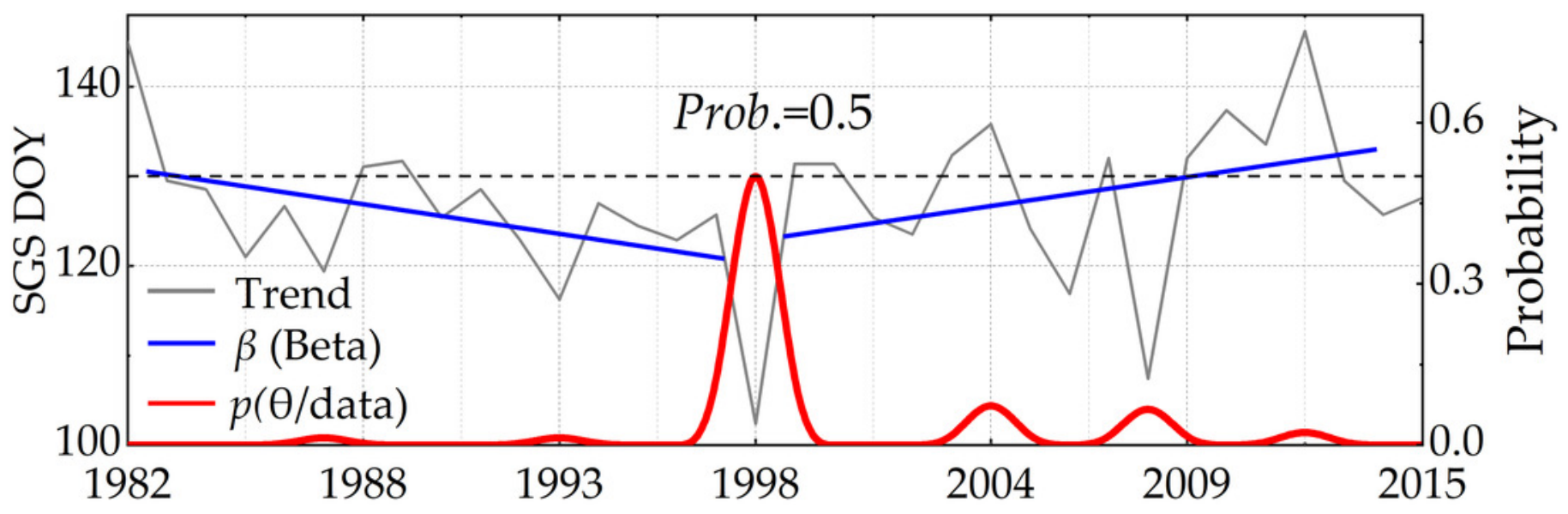


Figure 5

Flowchart of methodology used in this study.

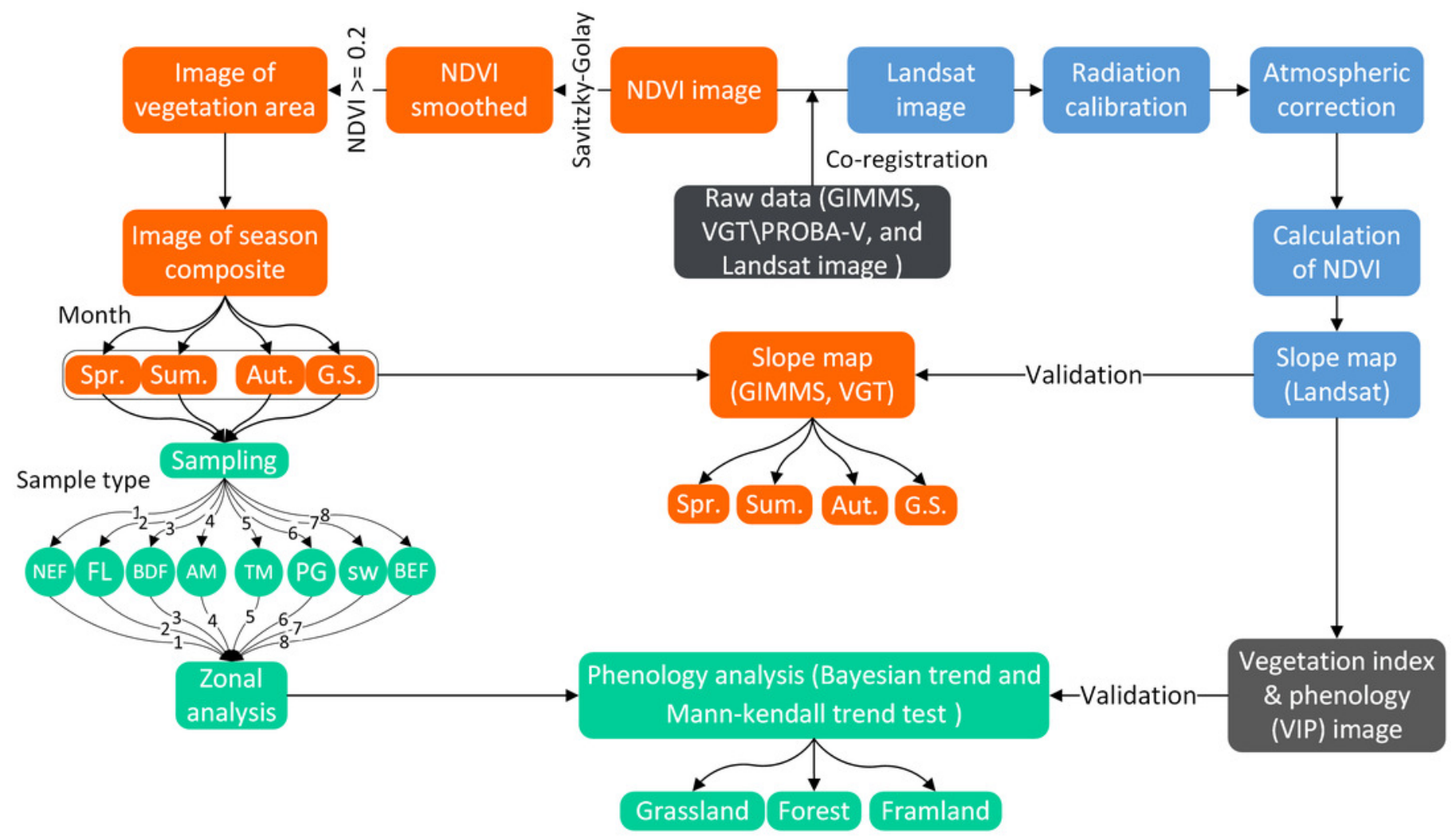


Figure 6

Trend and test of SGS and EGS from 1999 to 2018. The gray background area is the standard deviation (SD).

(A) Farmland. (B) Forest. (C) Grassland. (D) Farmland. (E) Forest. (F) Grassland. (G) Farmland. (H) Forest. (I) Grassland. (J) Farmland. (K) Forest. (L) Grassland.
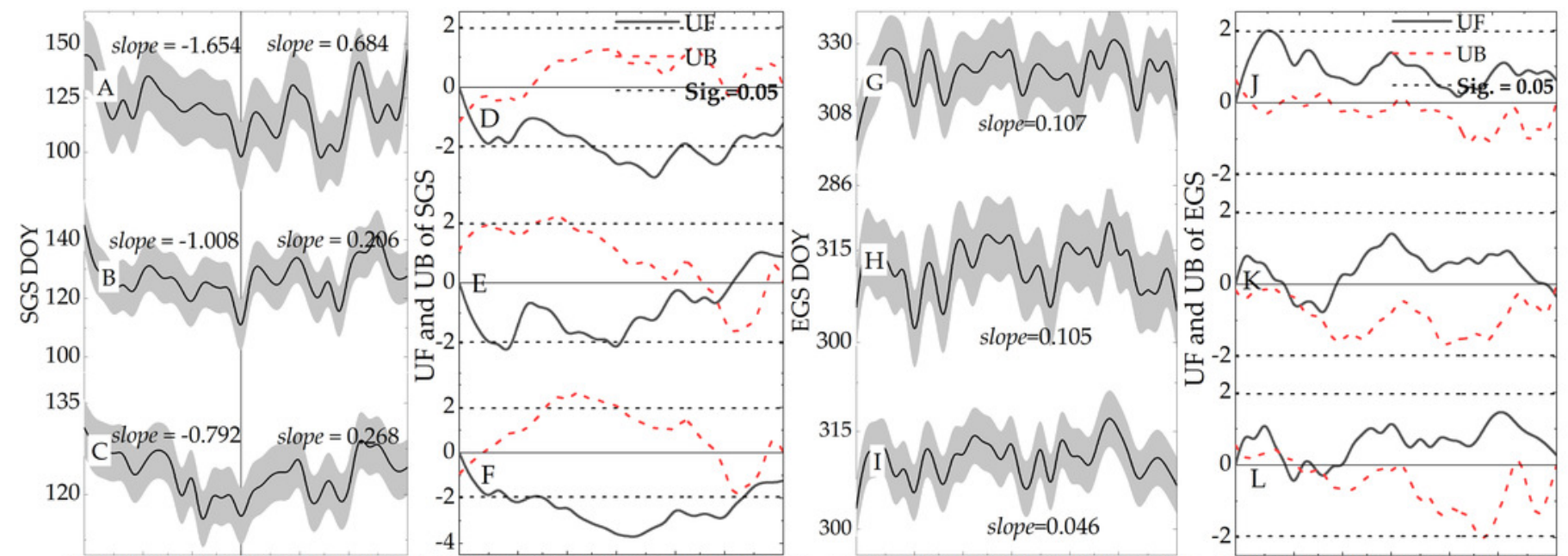

19821988199319982004200920151982198819931998200420092015

19821988199319982004200920151982198819931998200420092015 
Figure 7

Spatial distribution of the vegetation dynamics from 1982 to 2015.

(A) Spring. (B) Summer. (C) Autumn. (D) Growing season.
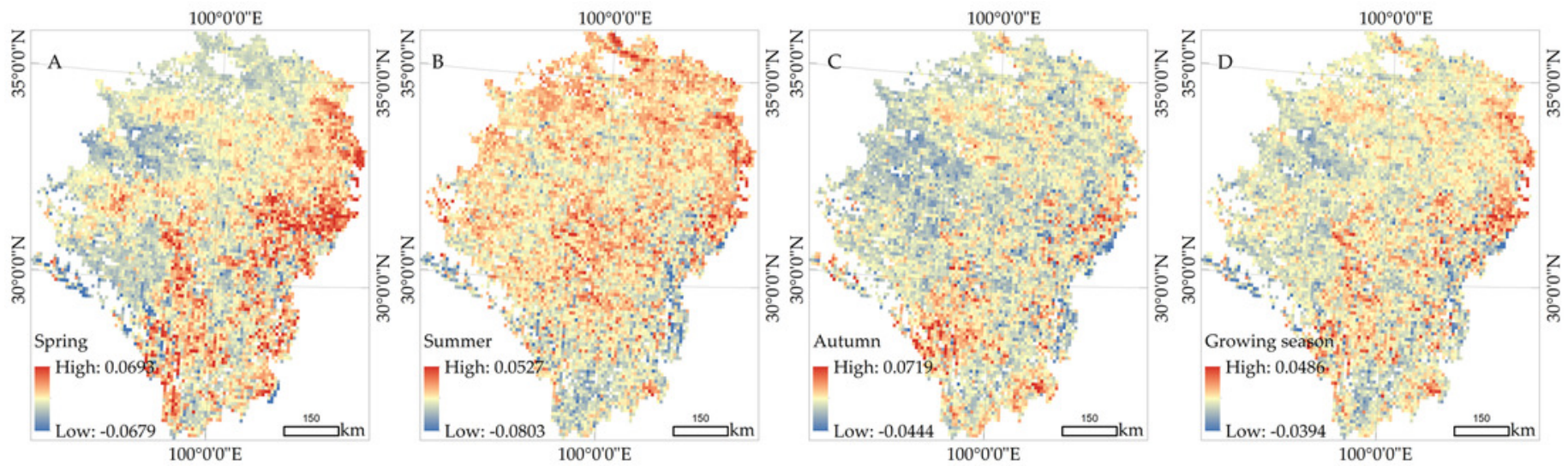
Figure 8

Spatial distribution of the vegetation dynamics from 1999 to 2015.

(A) Spring. (B) Summer. (C) Autumn. (D) Growing season. (E) Spring. (F) Summer. (G) Autumn. (H) Growing season.

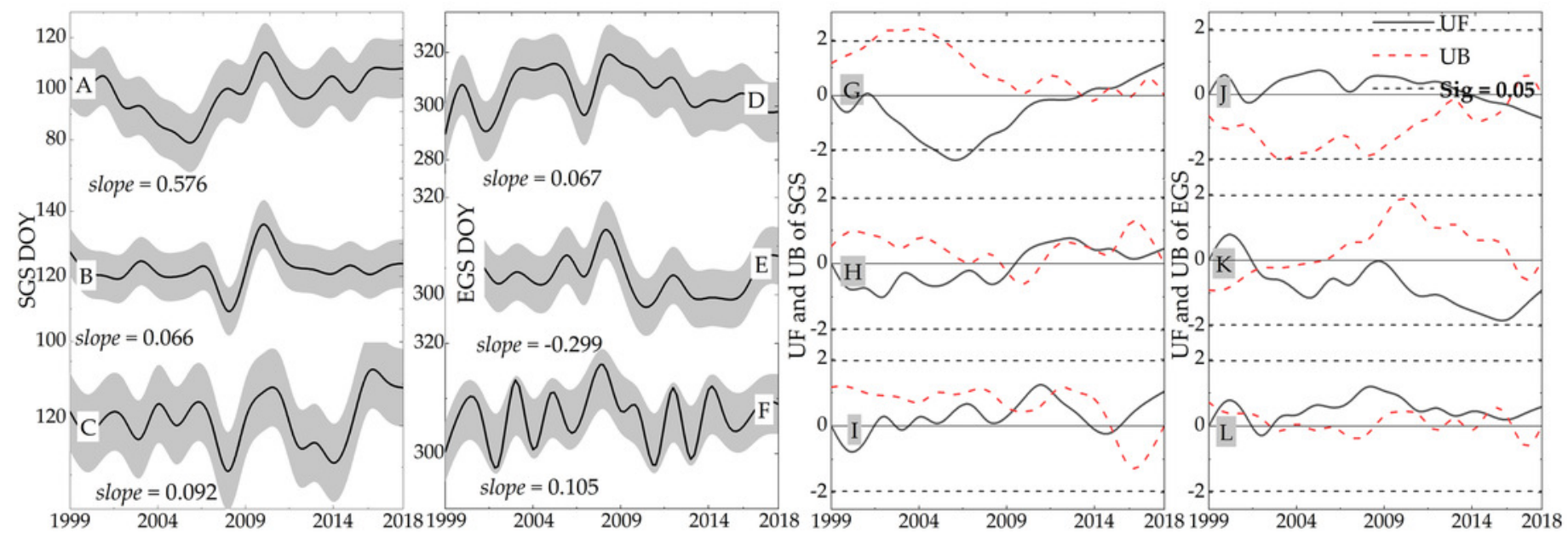


Figure 9

Spatial distribution of the vegetation dynamics in different seasons from 1999 to 2018.

(A) Spring. (B) Summer. (C) Autumn. (D) Growing season.
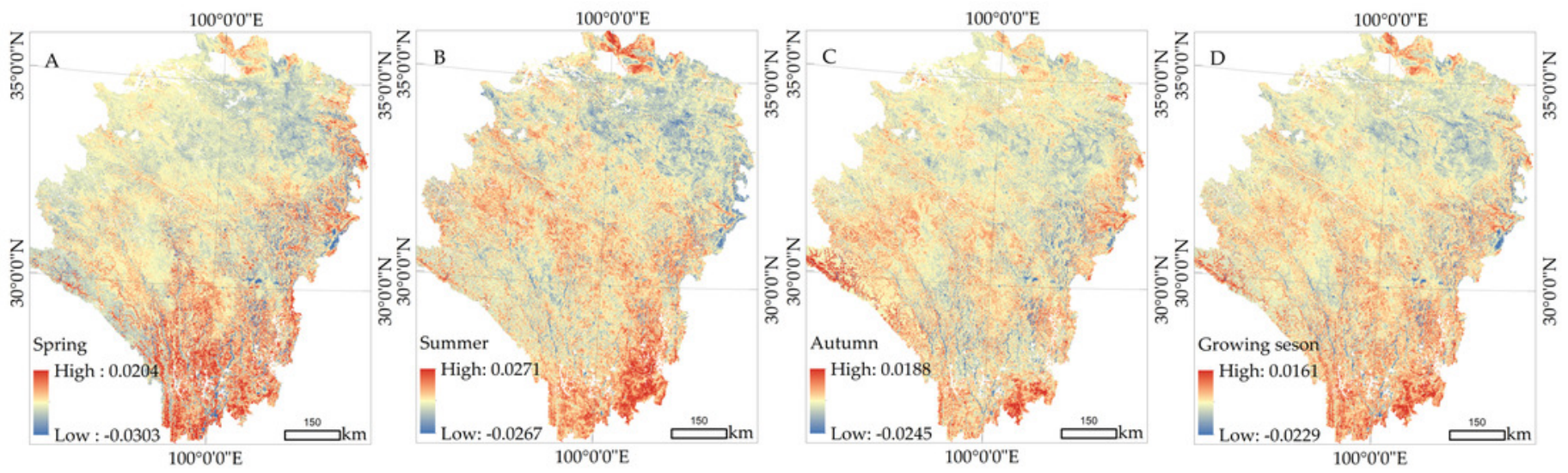


\section{Figure 10}

Spatial distribution of the vegetation dynamics from 1999 to 2015.

(A) Spring. (B) Summer. (C) Autumn. (D) Growing season. (E) Spring. (F) Summer. (G) Autumn. (H) Growing season.
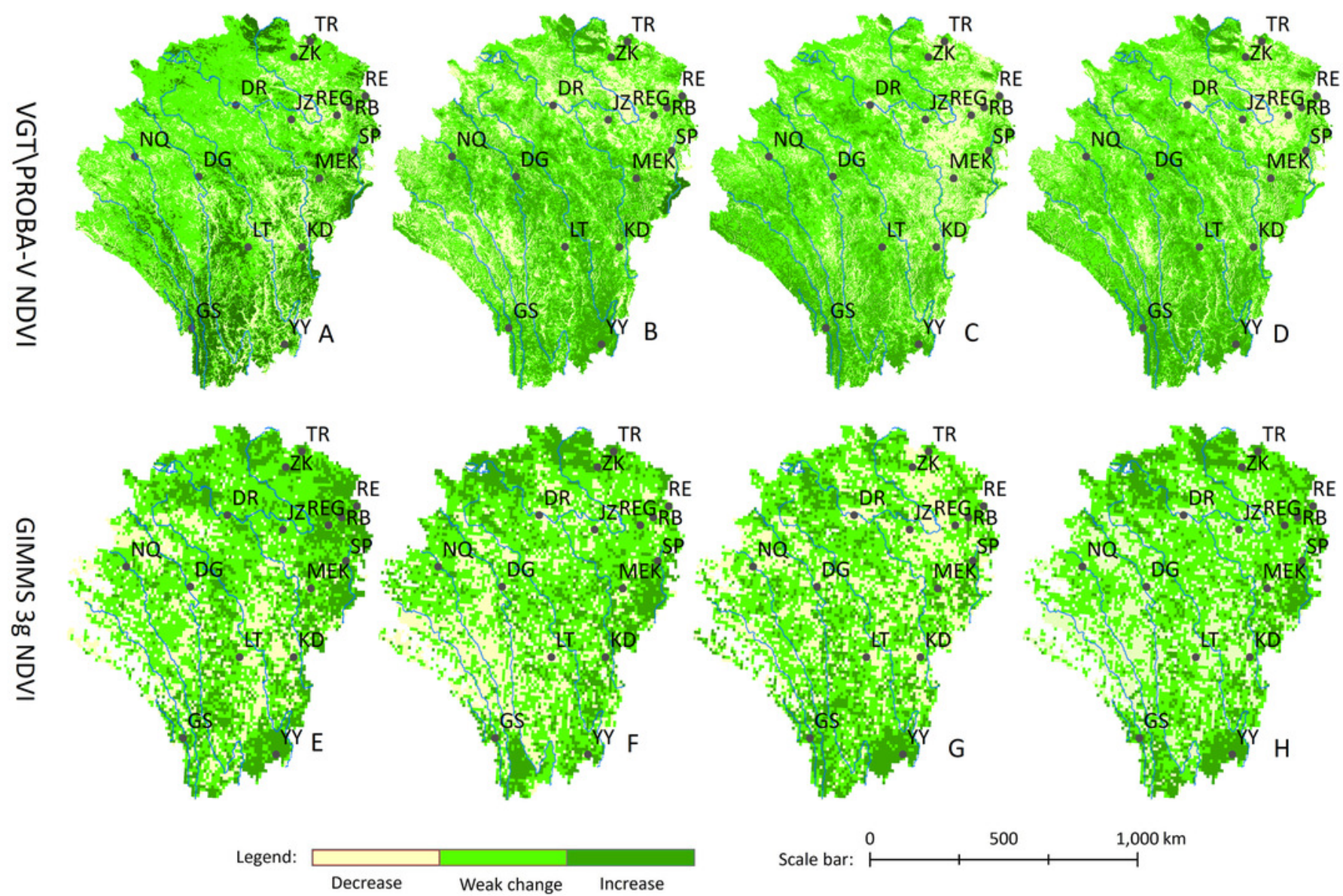
Figure 11

Trend of different vegetation at a site scale from 1999 to 2015.

(A) Spring. (B) Summer. (C) Autumn. (D) Growing season. (E) Spring. (F) Summer. (G) Autumn. (H) Growing season.

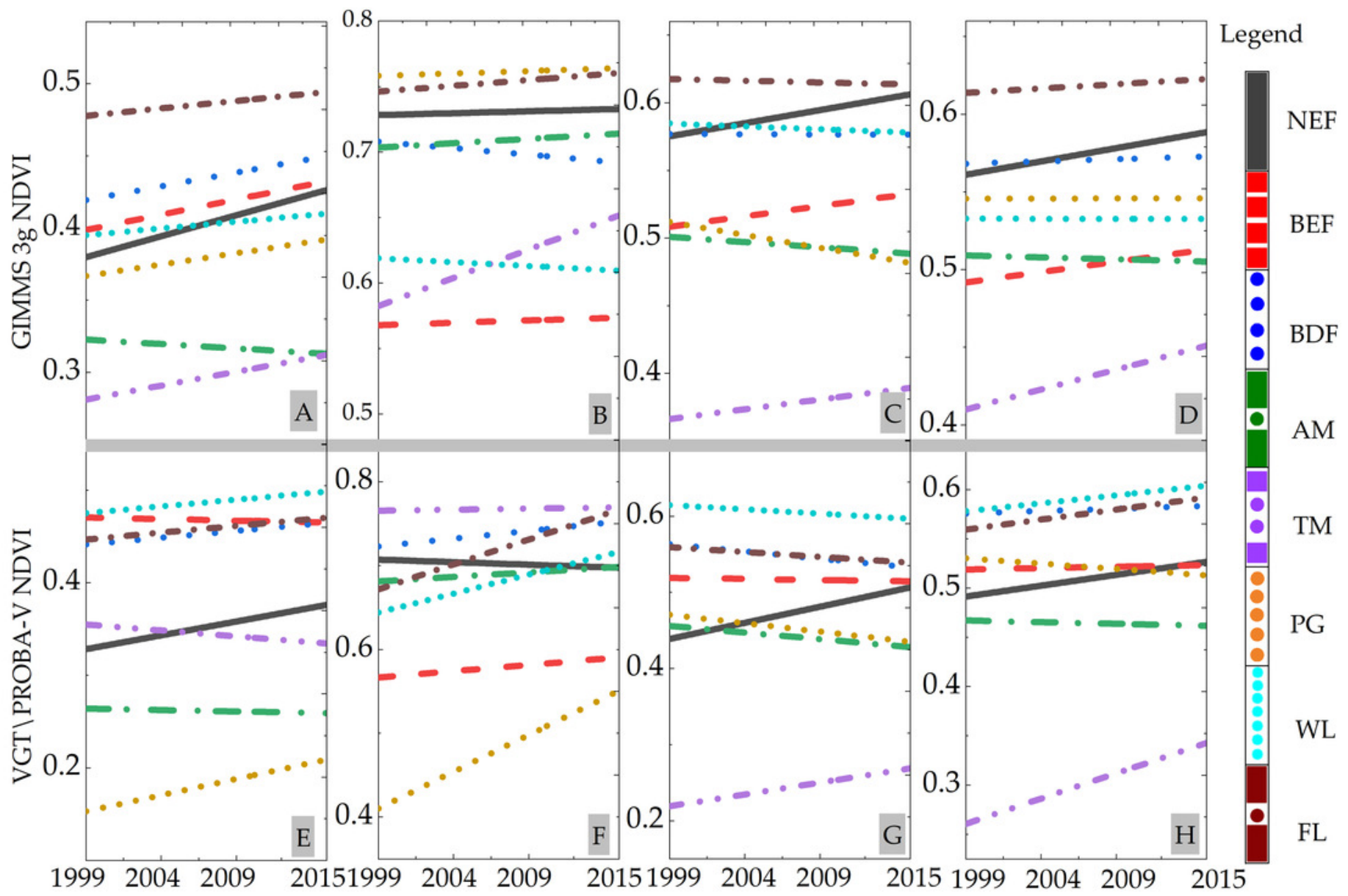




\section{Figure 12}

The trend and the confidence level of phenologicalchanges based on the Bayesian method.

Note: Blue solid line represents the continuous probability of trend change. Red solid line indicates the moment and probability of turning point occurring. Grey solid line denotes the change trend of raw data.

(A) Farmland. (B) Forest. (C) Grassland. (D) Farmland. (E) Forest. (F) Grassland.
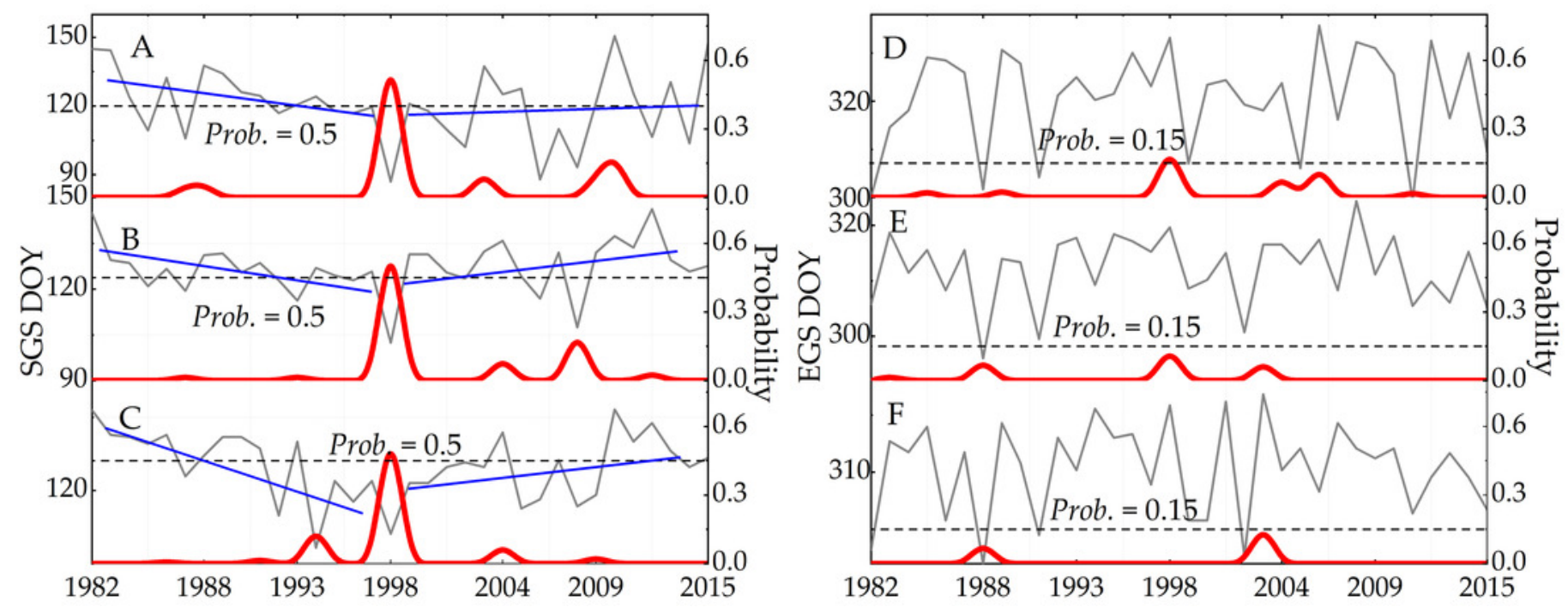


\section{Figure 13}

Using the data engine of VIP Lab to generate the global three-dimensional phenological grid (yearly product), including the start of growing season (SGS) and end of growing season (EGS).

Note: The data is a grid of spherical surface, and we only showed the section of the study area and surrounding areas.

(A), (B), (C) Spatial distribution of SGS. (D), (E), (F) Spatial distribution of EGS.

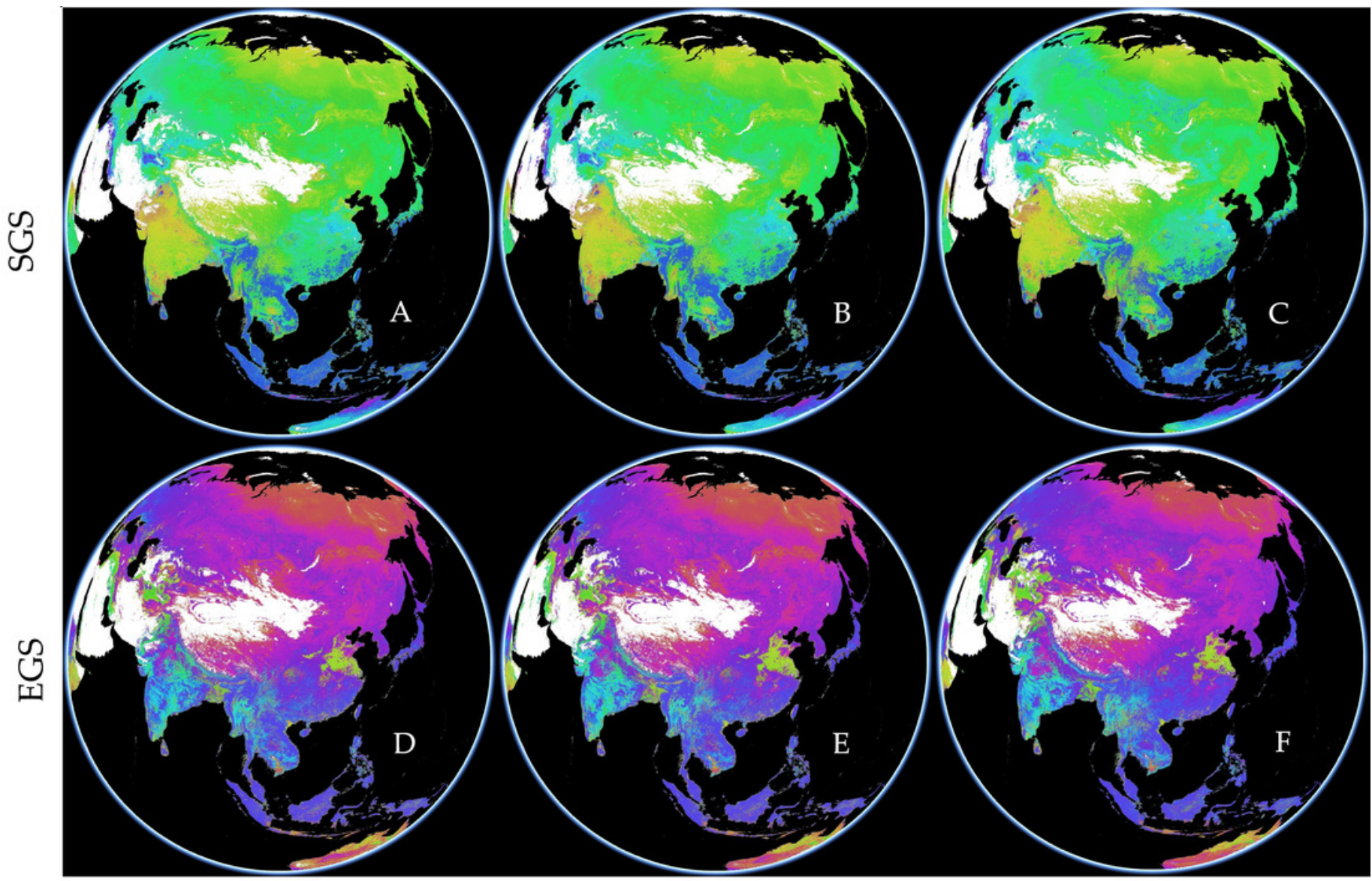

Day of the year

$\begin{array}{lllllllllllll}1 & 30 & 60 & 90 & 120 & 150 & 180 & 210 & 240 & 270 & 300 & 330 & 366\end{array}$

Legend

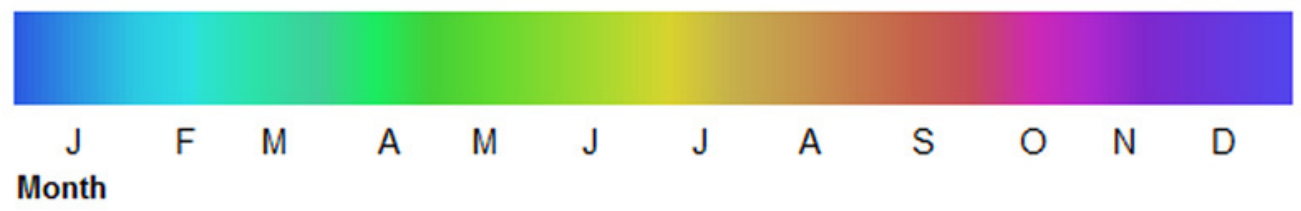


Figure 14

SGS and EGS of various vegetations were extracted from the VIP phenological grid, and the value extracted was used to validate the GIMMS $3 g$ NDVI-based phenological changes in specific year.

(A) 1982. (B) 1998. (C) 2015.

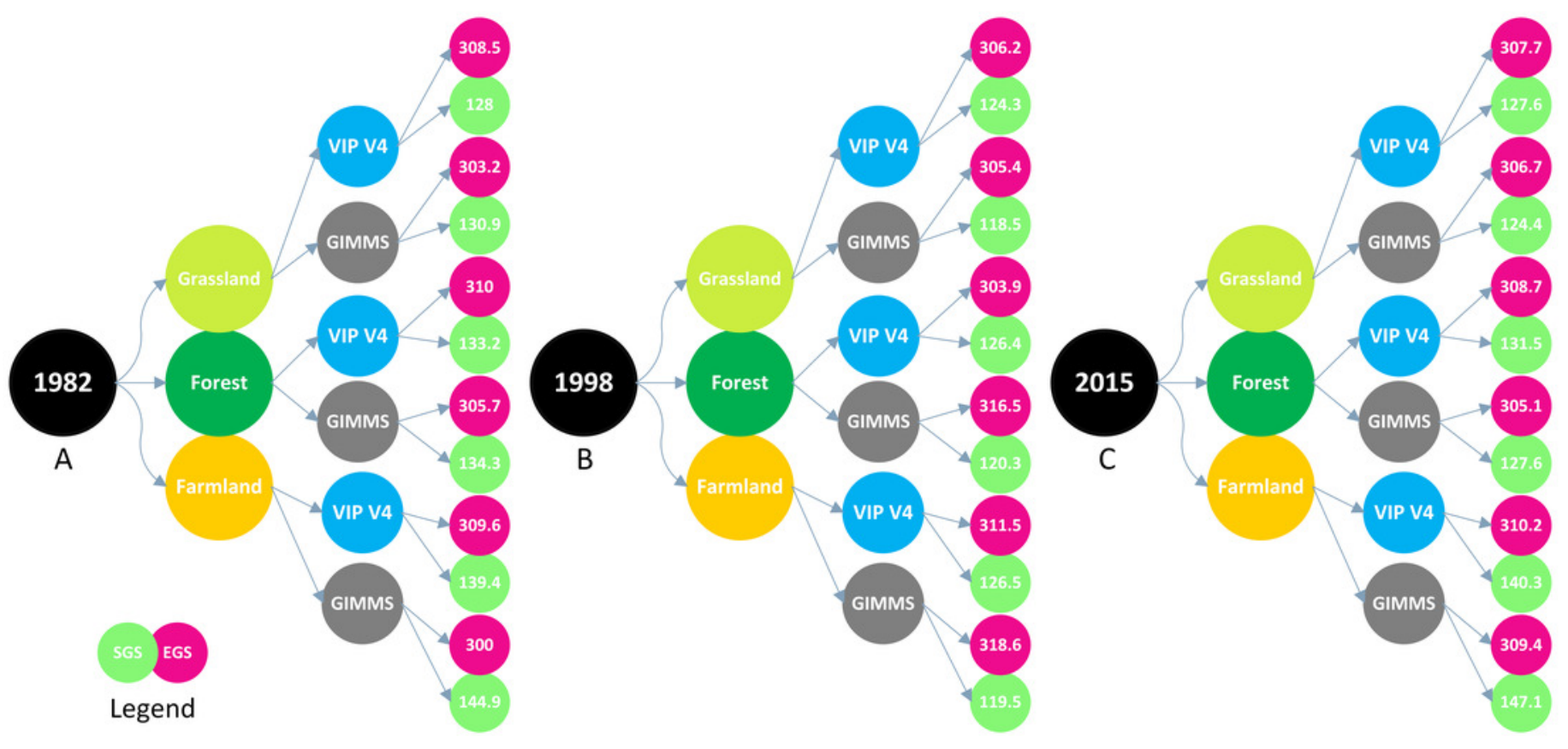




\section{Figure 15}

Validation of the vegetation dynamics from 1999 to $2015 . A, B$, and C is the slope of VGT\PROBA-V NDVI, the slope of Landsat NDVI, and true color image of Landsat OLI (2015/10/01), respectively.

(A) Slope of VGT NDVI. (B) Slope of Landsat NDVI. (C) Landsat 8 OLI image. (D) Site 1. (E) Site 2. (F) Site 3. (G) Site 4. (H) Site 5. (I) Site 1. (J) Site 2. (K) Site 3. (L) Site 4. (M) Site 5.
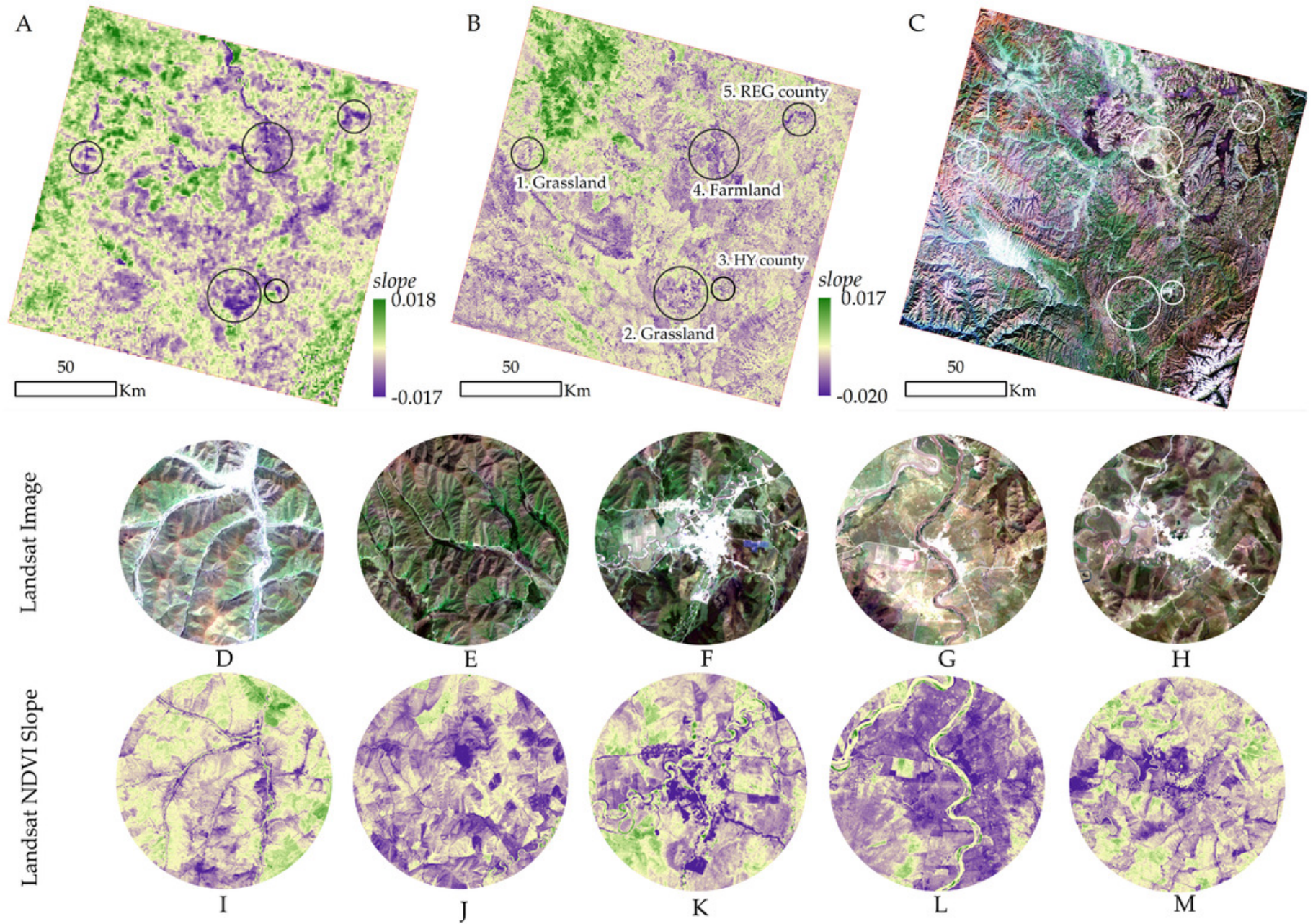


\section{Table $\mathbf{1}$ (on next page)}

Acquisition date and sensor of Landsat orthophotoused in this study 
1

Tab. 1 Acquisition date and sensor of Landsat orthophoto used in this study

\begin{tabular}{|c|c|c|c|c|c|c|c|c|c|c|}
\hline Path/Row & \multicolumn{10}{|c|}{$131 / 37$} \\
\hline Sensor & \multicolumn{8}{|c|}{ Landsat 5 TM } & \multicolumn{2}{|c|}{ Landsat $8 \mathrm{OLI}$} \\
\hline Date $(\mathrm{y} / \mathrm{m} / \mathrm{d})$ & 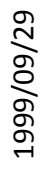 & 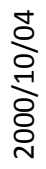 & $\begin{array}{l}\stackrel{ }{-} \\
\text { 엉 } \\
\stackrel{-}{\circ} \\
\stackrel{ }{\circ}\end{array}$ & 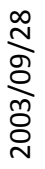 & 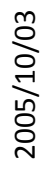 & 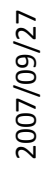 & 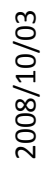 & 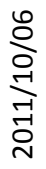 & 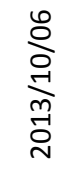 & 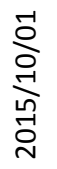 \\
\hline Resolution & \multicolumn{10}{|c|}{$30 \mathrm{~m}$} \\
\hline
\end{tabular}

2 


\section{Table 2 (on next page)}

Vegetation types and their use of the sample site. 
1

Tab. 2. Vegetation types and their use of the sample site

\begin{tabular}{|c|c|c|c|c|c|}
\hline Site & $\begin{array}{l}\text { Longitude } \\
\left({ }^{\circ} \mathrm{E}\right)\end{array}$ & $\begin{array}{l}\text { Latitude } \\
\left({ }^{\circ} \mathrm{N}\right)\end{array}$ & $\begin{array}{l}\text { Altitude } \\
\text { (m) }\end{array}$ & Vegetation type & Data use \\
\hline Songpan (SP) & 103.567 & 32.650 & 3732 & $\begin{array}{l}\text { Needle-leave } \\
\text { deciduous forest (NEF) }\end{array}$ & $\begin{array}{l}\text { Phenology analysis and } \\
\text { vegetation dynamic }\end{array}$ \\
\hline Ruobei (RB) & 103.894 & 34.105 & 3155 & \multirow{4}{*}{$\begin{array}{l}\text { Broadleaved deciduous } \\
\text { forest (BDF) }\end{array}$} & \multirow{4}{*}{ Vegetation dynamic } \\
\hline Zeku (ZK) & 101.504 & 35.094 & 3889 & & \\
\hline Gongshan (GS) & 98.667 & 27.750 & 2297 & & \\
\hline Yanyuan (YY) & 101.517 & 27.433 & 2571 & & \\
\hline Kangding (KD) & 101.967 & 30.050 & 4038 & \multirow{2}{*}{$\begin{array}{l}\text { Broadleaved evergreen } \\
\text { forest (BEF) }\end{array}$} & \multirow{2}{*}{ Vegetation dynamic } \\
\hline Litang (LT) & 100.267 & 30.000 & 4581 & & \\
\hline Jiuzhi (JZ) & 101.483 & 33.433 & 3985 & \multirow{3}{*}{ Alpine meadow (AM) } & \multirow{3}{*}{$\begin{array}{l}\text { Phenology analysis and } \\
\text { vegetation dynamic }\end{array}$} \\
\hline Drerong (DR) & 99.650 & 33.750 & 4396 & & \\
\hline Nangqian (NQ) & 96.483 & 32.20 & 3661 & & \\
\hline Tongren (TR) & 103.389 & 33.796 & 3164 & \multirow{2}{*}{ Typical meadow (TM) } & \multirow{2}{*}{ Vegetation dynamic } \\
\hline Dege (DG) & 98.583 & 31.800 & 3918 & & \\
\hline Ruoergai (REG) & 102.967 & 33.583 & 3444 & Plain grassland (PG) & Vegetation dynamic \\
\hline Maerkang (MEK) & 102.451 & 31.896 & 4708 & Swamp (SW) & Vegetation dynamic \\
\hline Ruoe (RE) & 102.017 & 35.517 & 3229 & Farm land (FL) & $\begin{array}{l}\text { Phenology analysis and } \\
\text { vegetation dynamic }\end{array}$ \\
\hline
\end{tabular}

